Intuitive Biological Thought: Developmental Changes and Effects of Biology Education in

\title{
Late Adolescence
}

\author{
John D. Coley ${ }^{1}$, Melanie Arenson ${ }^{1,2},{\text { Yian } \mathrm{Xu}^{1}, \text { \& Kimberly Tanner }}^{3}$ \\ ${ }^{1}$ Department of Psychology, Northeastern University \\ ${ }^{2}$ Department of Medicine, University of California, San Francisco \& San Francisco VA Medical \\ Center \\ ${ }^{3}$ Department of Biology, San Francisco State University
}

Corresponding Author:

John D. Coley

Department of Psychology

125 Nightingale Hall

Northeastern University

360 Huntington Avenue

Boston, MA 02115

j.coley@northeastern.edu 


\begin{abstract}
A large body of cognitive research has shown that people intuitively and effortlessly reason about the biological world in complex and systematic ways. We addressed two questions about the nature of intuitive biological reasoning: How does intuitive biological thinking change during adolescence and early adulthood? How does increasing biology education influence intuitive biological thinking? To do so, we developed a battery of measures to systematically test three components of intuitive biological thought: anthropocentric thinking, teleological thinking and essentialist thinking, and tested 8th graders and university students (both biology majors, and non-biology majors). Results reveal clear evidence of persistent intuitive reasoning among all populations studied, consistent but surprisingly small differences between 8th graders and college students on measures of intuitive biological thought, and consistent but again surprisingly small influence of increasing biology education on intuitive biological reasoning. Results speak to the persistence of intuitive reasoning, the importance of taking intuitive knowledge into account in science classrooms, and the necessity of interdisciplinary research to advance biology education. Further studies are necessary to investigate how cultural context and continued acquisition of expertise impact intuitive biology thinking.
\end{abstract}

Key words: Intuitive biology, science education, conceptual change, psychological essentialism, anthropocentrism, teleology 


\section{Introduction}

Cognitive scientists and educators alike acknowledge that students do not arrive at the science classroom as blank slates, but rather have developed complex and adaptive intuitive conceptual systems for understanding the world around them. As such, science education results from the interplay between students' intuitive ways of knowing and scientific concepts introduced by expert instructors, across a range of STEM disciplines, including physics (e.g., Chi, 1992; DiSessa, 1993; Vosniadou \& Brewer, 1992), chemistry (Maeyer \& Talanquer, 2010), and biology (Kelemen, Rottman \& Seston, 2013, Shtulman 2006, Coley \& Tanner, 2012, 2015). As such, it is critically important to understand the nature and content of intuitive understandings to inform science education. In this paper, we investigate the development of intuitive biological thought in adolescence and young adulthood, and begin to explore potential impacts of increasing science education on this intuitive conceptual system.

\subsection{Cognitive Construals in Intuitive Biological Thought}

Humans naturally, intuitively, and effortlessly reason about biological entities, structures, processes, and phenomena in predictable ways (e.g., Carey, 1985; Brown, 1984; Berlin, 1992; Coley, Solomon \& Shafto, 2002; Medin \& Atran, 2004; Inagaki \& Hatano, 2006; Atran \& Medin, 2008). Elsewhere, we have dubbed these regularities cognitive construals (Coley \& Tanner, 2012, 2015). A cognitive construal is an intuitive, often implicit, way of thinking about the world. It might be a set of assumptions, a type of explanation, or a predisposition to a particular type of reasoning. Three such cognitive construals - teleological thinking, essentialist thinking, and anthropocentric thinking - recur in research on the development of intuitive biological thought. Framing intuitive biological thought in terms of these three construals is a 
useful way to represent a large and disparate literature. We do not claim that this list is exhaustive, nor do we claim that these construals are exclusively relevant to thinking about biology. Rather, we focus on these three construals because they have received the bulk of attention in the cognitive and developmental literature, and we have shown that they are linked to scientific misconceptions in previous work (Coley \& Tanner, 2015). In the following, we briefly describe each construal, its role in intuitive biological thought, and its developmental trajectory. 


\subsubsection{Anthropocentric Thinking}

Anthropocentric thinking can involve the tendency to attribute human characteristics to non-human or inanimate objects (e.g., Piaget, 1929; Richards \& Siegler, 1986), to use humans as a default analogical base for reasoning about biological species or processes (e.g., Carey, 1985; Inagaki \& Hatano, 1991), or to see humans as unique and biologically discontinuous with the rest of the animal world. Although undoubtedly useful for adaptive reasoning and social cognition, anthropocentric thinking can result in misrepresentation of the place of human beings in the natural world. Such "human exceptionalism" (Gee, 2013), involves the way in which human beings are incorporated into the intuitive taxonomy of living things. According to geneticists, humans are African great apes; we share a common ancestor who lived c. 5-8 million years ago with our closest living relative: chimpanzees. However, intuitive biological taxonomies - particularly those found in industrialized western societies - tend to see humans as essentially separate from other species (Coley, 2007; Johnson, et al., 1992). Likewise, undergraduate students are also slower and less accurate at classifying plants - as compared to animals - as living things (Goldberg \& Thomson-Schill, 2009); this is consistent with anthropocentric thinking because it suggests that students are less likely to apply universal biological properties to organisms that are highly dissimilar to humans.

Developmental psychologists have paid little attention to the development of anthropocentric thinking past the age of 10. Although some studies document a shift from human-based analogical reasoning to category-based attribution of biological properties (e.g., Carey, 1985; Inagaki \& Sugiyama, 1988), research with children reveals a persistent reluctance to classify humans with other animals (e.g., Coley, 2007; Johnson, et al., 1992; Leddon et al., 2012) or to attribute core biological properties, which are familiar in humans, to nonhuman 
organisms dissimilar to humans, particularly plants (Richards \& Siegler, 1986; Arenson \& Coley, 2016). As such, the degree to which anthropocentric thinking persists into young adulthood remains an open question.

\subsubsection{Teleological Thinking}

Teleological thinking is causal reasoning in which a goal, purpose, function, or outcome of an event is taken as the cause of that event (Keil, 2006; Talanquer, 2009, 2013). Kelemen (1999) argues that teleological thinking is a central component of adults' everyday thought. For example, people appropriately make the teleological assumptions that human actions are directed toward certain goals, and that human artifacts, such as chairs and coats, are designed by their creators to fulfill some intended purpose. In intuitive biology, people likewise apply teleological thinking to explain biological entities, structures and processes, as if biological phenomena are deliberately designed to serve a purpose just as human actions and artifacts do. As Kelemen emphasizes, teleological thinking provides an important component of adults' intuitive interpretations of why events occur or why objects have the properties that they do. Although the causes, origins, and nature of teleological thinking are the subjects of considerable debate (e.g., Lombrozo \& Carey, 2006; Kelemen, 2004; ojalehto, Waxman \& Medin, 2013) this construal seems to be an integral part of intuitive thinking about biology.

The developmental arc of teleological thinking involves a pattern of "pruning." Kelemen has shown that teleological thinking is widespread (or in her terms, "promiscuous") among young children and becomes increasingly selective (Kelemen, 1999, 2012). In one study, 6-yearolds favored teleological explanations for a broad range of phenomena, including properties of nonliving objects (e.g., "The rocks were pointy so that animals wouldn't sit on them and smash them") and animals (e.g., birds exist "for flying," lions exist "to go in the zoo"). College students 
were more selective, but still utilized teleological thinking in a biological context. Indeed, Kelemen and Rossett (2009) found that undergraduates endorsed unwarranted teleological statements about biological phenomena (e.g., "Earthworms tunnel underground to aerate the soil") $35 \%$ of the time, and that under time pressure, this figure increased to $51 \%$. Thus, teleological thinking appears to become more narrowly applied, but does not disappear in adults.

\subsubsection{Essentialist Thinking}

Essentialist thinking captures the idea that in addition to summarizing knowledge, concepts also involve a possibly implicit assumption that some unobservable essential property (an "underlying reality" or "true nature") conveys category identity and causes observable similarities among category members (Medin \& Ortony, 1989; Ahn et al., 2001; Gelman, 2003). Although essentialist thinking provides us with an important tool to reduce the complexity of incoming information, and allows us to organize what we know and make inferences about what we don't know, it can also lead to overgeneralization or unwarranted assumptions of homogeneity. In intuitive biology, essentialist thinking may encourage reasoning that assumes a core underlying property or feature of a biological structure, species, or system determines its overt features and identity. For example, essentialist thinking leads to the idea that superficial transformations (e.g., changes in appearance) should not affect category membership, which is ultimately based on the presence or lack of an underlying essential property, rather than superficial features (Keil, 1989; Rips, 1989; but see Hampton et al. 2007). Another consequence of essentialist thinking is that members of a category are relatively uniform with respect to shared properties - a shared essence should give rise to similar properties in all category members (e.g., Shtulman \& Shultz, 2008), leading us to underestimate variability. A third consequence of essentialist thinking is that category membership conveys innate potential: 
because of an underlying essence, category members not only share the same properties, but also share the propensity to develop the same characteristics over time (e.g., Gelman \& Wellman, 1991; Solomon et al., 1996). In sum, essentialist thinking yields assumptions—about the naturalness and uniformity of category members - which reduce the complexity of incoming information.

Like teleological thinking, the development of essentialist thinking involves increasing selectivity. There is substantial evidence suggesting that essentialist thinking is an early and pervasive cognitive bias (see Gelman, 2003). Preschool children are often overzealous in their essentialist thinking; for example, preschoolers tend to predict that offspring will resemble birth parents with respect to characteristics ranging from biological properties like eye color to behavioral properties like beliefs. Undergraduates are more selective, and tend to predict that offspring will resemble birth parents with respect to physical characteristics, but adoptive parents with respect to beliefs and preferences (e.g., Taylor et al., 2009; Eidson \& Coley, 2014). Although scant research has explicitly examined changes in essentialist thinking between elementary school and young adulthood, the literature is somewhat equivocal about essentialist thinking in adults. For instance, Medin and Atran (2004) argue that essentialist thinking is a pervasive aspect of intuitive biological thought across diverse cultures, Diesendruck and Gelman (1999) argue that membership in biological kinds is more likely to be seen as absolute, and numerous studies of category-based inference in adults (e.g., Feeney \& Heit, 2007; Coley \& Vasilyeva, 2010) are consistent with essentialist thinking. In contrast, Kalish (2002) argues that membership in biological kinds may not always be perceived as absolute, and Hampton, Estes \& Simmons (2007) argue that membership in biological categories is surprisingly malleable. Thus, 
the developmental trajectory — and indeed, the adult "endpoint" —of essentialist thinking is complex and not entirely understood at present.

\subsection{The Influence of Increasing Biology Education on Intuitive Biological Reasoning}

Anthropocentric, teleological, and essentialist thinking represent powerful, useful, and adaptive principles for organizing what we know about the biological world, and allowing us to make predictions about what we don't know. Although understanding the development of these construals into adulthood is important in its own right (Coley, 2000), documenting the nature of informal intuitive biology in young adults becomes even more important in light of the fact that cognitive construals may interact with scientific reasoning in unanticipated ways and may have specific implications for science education (e.g., Coley \& Tanner, 2012, 2015; Evans, 2008, 2013; Evans et al. 2012; Nehm, 2010; Nehm \& Ridgeway, 2011; Opfer, Nehm \& Ha, 2012; Rosengren, Brem, Evans \& Sinatra, 2012; Talanquer, 2006). For example, measures of both teleological and essentialist thinking have been shown to predict students' understanding of evolution by natural selection (e.g., Kelemen \& Rosset, 2009; Shtulman \& Schulz, 2008). Other evidence shows that even trained and practicing scientists show implicit evidence of residual construal-based thinking (e.g., Kelemen et al. 2013; Goldberg \& Thompson-Schill, 2009) and that construal-based language present in biology majors' explanations is associated with acceptance of related scientific misconceptions (Coley \& Tanner, 2015). However, to our knowledge no study has systematically explored the impact of increasing levels of life science education on intuitive biological thought.

This question is important because it addresses the potential depth and generality of emerging disciplinary expertise resulting from increasing amounts of formal biology education. On one hand, formal education in biology might replace intuitive construals with more accurate, 
normative thinking about biological structure and function. If so, we might expect intuitive biological thought to weaken or disappear among biology students. Alternatively, formal biology education might provide students with an alternative explanatory framework that coexists alongside intuitive biology, but does not replace it (e.g., Legare, Evans, Rosengren \& Harris, 2012; Shtulman \& Valcarcel, 2012). If so, we might expect intuitive biological thought to persist among biology students.

\subsection{Current Study}

The current study aims to investigate two questions: 1) What is the developmental trajectory of construal-based intuitive biological thinking beyond childhood, into adolescence and early adulthood? 2) How do increasing amounts of biology education influence the developmental trajectory of intuitive biological thinking? In contrast to previous studies which have mostly focused on a single construal and utilized a single measure to test for its presence (with few exceptions, e.g., Johnson \& Carey, 1998), we developed a battery of multiple measures to systematically assess anthropocentric, teleological, and essentialist thinking. We administered this battery to three groups of participants with increasing amounts of biology education: 8th graders (who have experienced a standard middle school life science course), undergraduate nonscience majors (who have experienced both a standard middle school and a standard high school life science course), and undergraduate biology majors (who have experienced both a standard middle school life science course, as well as an intensive, college-level life science course). By comparing 8th graders to non-majors, we can examine developmental differences between populations that have experienced standard life science education through typical secondary science curricula; such differences could reflect developmental change between early adolescence and early adulthood, as well as increasing amounts of biology education. By 
comparing biology majors to non-science majors, we can gauge the effects of even more extensive biology education on intuitive biological reasoning between populations at a similar developmental stage.

\section{Method}

\subsection{Participants}

A total of 211 individuals participated in the study. These were drawn from three groups. Biology majors $(\mathrm{N}=69)$ were first-year undergraduate students at Northeastern University who were enrolled in three sections of a seminar for first-year biology, biochemistry, and behavioral neuroscience majors with Advanced Placement (AP) biology credit. As such, these students were at the beginning of their university-level studies in biology, but had all taken AP biology courses in high school and achieved a score of 4 or 5 on the AP Biology exam. Importantly, while these students had declared their intention to major in biology and received AP biology credit, they had not yet experienced a university biology course. Non-majors $(\mathrm{N}=68)$ were students enrolled in an introductory psychology course. Non-majors were pre-screened to ensure that they met two criteria: (1) that they were not majoring in biology, biochemistry, or behavioral neuroscience (non-majors represented a wide variety of majors, most of which were in the humanities and social sciences) and (2) that they had earned AP credit in some subject other than biology. This was to roughly equate general academic ability for the two undergraduate groups. Finally, $8^{\text {th }}$ graders $(\mathrm{N}=74)$ were students enrolled in a standard $8^{\text {th }}$ grade science class at a suburban public middle school in a medium-sized town outside of Boston, Massachusetts. Biology majors and $8^{\text {th }}$ graders participated as part of their normal classroom activities; non-majors participated to partially fulfill a course research requirement. 


\subsection{Design}

We designed a written survey comprised of measures of three different cognitive construals (Coley \& Tanner, 2012, 2015) relevant to intuitive biological reasoning: essentialist thinking, anthropocentric thinking, and teleological thinking. Most measures were borrowed and adapted from published reports. Two forms of the survey were constructed. Measures appeared on the survey in a randomly determined order, with the constraint that different components of the same measure did not appear consecutively. The order on Form B was the reverse of Form A. Half of the participants in each group received Form A, and half received Form B. Some measures were identical on both forms, but most were comparable in structure and intent but differed in specific exemplars, to maximize the number of items measuring any given construct across all participants. Measures are summarized in Table 1, and described in detail in the Appendix.

$<$ Table 1 $>$

\subsection{Procedure}

Biology majors were tested in class for a full class period at the beginning of the academic year, and $8^{\text {th }}$ graders were tested in class several months into the academic year. In both cases, the survey was distributed and students were told to take their time and answer carefully. Non-majors were tested individually or in small groups in a laboratory setting, and were given the same instructions. In all cases, the survey on intuitive biological thought was administered along with a survey on biological misconceptions (see Coley \& Tanner, 2015). Completion of the surveys typically took 45-50 minutes. 


\section{Results}

We present the results in four sections. First, for each of the three target cognitive construals, we present a detailed analysis of performance on corresponding measures. For each measure, we will present a comparison of the three groups on a summary statistic, followed by a more detailed analysis of performance on that specific measure. In the fourth section, we compare $8^{\text {th }}$ graders, non-majors, and biology majors on composite scores for each of our three target cognitive construals. This provides an overview of our findings and a summary of group comparisons in terms of essentialist, anthropocentric, and teleological thinking.

\subsection{Anthropocentric Thinking}

The component of anthropocentric thinking we focused on was "human exceptionalism," the idea that humans as a species are biologically unique, separate, and distinct from the rest of the natural world.

\subsubsection{Common Ancestor}

For this task, participants were given a list of biological categories ranging from great apes to plants, and asked which of them shared a common ancestor with humans. Any indication that humans do not share common ancestry with another species was taken to demonstrate anthropocentric thinking. To index anthropocentric thinking in the three groups, we summed the number of positive responses (out of a possible score of seven) and compared means across the three groups (see Figure 1A). Biology majors reported more species shared common ancestry with humans than did non-majors or $8^{\text {th }}$ graders, who did not differ from each other, $F(2,202)=19.14, p<0.001, \eta^{2}=0.16$, Tukey HSD $p<0.001$. 
To examine responses in more detail, we computed the percentage of positive responses for each specific target category for each group (see Figure 1B). We examined these data in two ways. First, we compared each cell to chance performance (50\%) via binomial test; abovechance performance suggests consensual endorsement of common ancestry, whereas belowchance performance indicates systematic denial of common ancestry and chance performance reflects lack of consensus. On this metric, all three groups endorsed common ancestry with apes (binomial $p<0.001$ ). Eighth graders and non-majors both denied common ancestry with humans for all remaining categories (binomial $p<0.001$ ). In contrast, biology majors endorsed common ancestry with mammals (binomial $p<0.001$ ) showed no consensus on common ancestry for dinosaurs, birds, reptiles or insects (binomial $p>0.336$ ), and denied common ancestry with plants (binomial $p=0.008)$.

Second, we ran 3 (Group) x 2 (Response) Chi Square analyses for each target category to compare responses among the three groups (see Figure 1B). For apes, groups did not differ $\left(X^{2}(2,208)=2.07, p=0.355\right)$ because virtually all participants acknowledged that humans and apes shared a common ancestor. For all other targets, biology majors endorsed shared common ancestry more frequently than non-majors or $8^{\text {th }}$ graders $\left(X^{2}(2,208)>14.55, p \leq 0.001\right)$. When biology majors were excluded from the analysis, non-majors and $8^{\text {th }}$ graders did not differ in their endorsement of common ancestry for mammals or plants $\left(X^{2}(1,139)<1.94, p>0.165\right)$. Although affirming common ancestry for other targets (dinosaur, bird, amphibian, insect) was quite rare, non-majors nevertheless did so more frequently than $8^{\text {th }}$ graders $\left(X^{2}(1,139)>4.22\right.$, $p<0.040)$. 


\subsubsection{Property Projection}

For this measure, participants rated the likelihood that a novel gene found in humans would also be found in a range of organisms varying in their degree of perceived similarity to humans (gorilla, deer, squirrel, sparrow, frog, grasshopper, daisy). Participants indicated their estimate of the likelihood that each target species would share a gene with humans on a scale of 1 (very unlikely) to 7 (very likely). Reasoning grounded in human uniqueness indicating anthropocentric thinking would be manifest in an unwillingness to attribute a human biological property to other organisms. To index overall anthropocentric thinking on this measure, we examined mean likelihood ratings for the three groups via one-way ANOVA, which revealed that groups differed in their mean likelihood ratings, $F(2,209)=10.79, p<0.001, \eta^{2}=0.09$, see Figure 2A. Specifically, biology majors gave higher ratings on average than non-majors (Tukey HSD $p=0.043$ ) or 8 th graders (Tukey HSD $p<0.001)$. Mean ratings for non-majors were marginally higher than for $8^{\text {th }}$ graders (Tukey HSD $p=0.078$ ).

\section{$<$ Figure 2 $>$}

To examine response patterns in more detail, we compared mean likelihood ratings via 3 (Group) x 7 (Target) mixed ANOVA. Several findings emerged in addition to the overall group differences discussed above. First, mean ratings varied by target species, $F(6,1218)=443.74$, $p<0.001, \eta^{2}=0.67$. To examine specific response patterns, we arranged targets in order of perceived similarity to humans and compared mean likelihood ratings for adjacent targets via ttests. ${ }^{1}$ To control for six comparisons, we used a critical p-value of 0.008 for each comparison.

\footnotetext{
${ }^{1}$ Although squirrels are phylogenetically more closely related to humans than deer are (e.g., Asher et al., 2009; Madsen et al., 2001), pilot testing revealed that participants generally perceive deer to be more similar to humans than squirrels.
} 
Using this method, mean ratings for each target differed from those for adjacent targets, except for sparrow and frog, which did not differ.

Finally, the effects of group and target were qualified by a group $\mathrm{x}$ target interaction, $\left(F(12,1218)=7.57, p<0.001, \eta^{2}=0.02\right)$. To explore this interaction, we conducted t-tests comparing mean likelihood ratings for each species with the adjacent species separately for each group, using the modification described above to control for multiple comparisons. As depicted in Figure $2 B$, inference patterns were highly similar, with the exception that for $8^{\text {th }}$ graders, inferences were somewhat less differentiated than for undergraduates.

In sum, even though biology majors were more willing to project a novel gene from humans to nonhumans than non-majors or $8^{\text {th }}$ graders, patterns of projection to different targets were remarkably similar across the three groups, as indicated by a linear decrease from gorilla through daisy.

\subsubsection{Biological Similarity}

This measure consisted of five triplets consisting of pictures of a human and two other species. Participants indicated which two were most biologically similar. In each case, the normative answer was to choose the human and one non-human. Responses were scored as correct (pairing the human with the more closely related non-human species), anthropocentric (pairing the two non-humans together), or other. To index overall anthropocentric thinking on this measure, we simply summed the number of anthropocentric responses for each participant, out of a possible five items (see Figure 3A), and compared groups via one-way ANOVA. On this analysis, biology majors made fewer anthropocentric responses than $8^{\text {th }}$ graders, and marginally fewer than non-majors, $F(2,208)=5.30, p=0.006, \eta^{2}=0.05$, Tukey HSD $p=0.005$ and $p=0.062$, respectively. Non-majors and $8^{\text {th }}$ graders did not differ on this measure. 
$<$ Figure $3>$

To look at responses in more detail, we classified each participant with respect to a consistent response pattern across all five items, based on whether the majority of responses (three or more out of five) were correct or anthropocentric. The few participants who showed neither consistent pattern were classified as “other." A 3 (Group) x 3 (Response Pattern) Chi Square analysis revealed group differences in the distribution of response patterns, $X^{2}(4,211)=12.52, p=0.014$. The distribution of response patterns is presented in Figure $3 \mathrm{~B}$, which shows that anthropocentric responding was the modal pattern for non-majors and $8^{\text {th }}$ graders, whereas correct responding was the modal pattern for biology majors. As with the previous task, this result suggests a more normative understanding of biological similarity among biology majors, but also a strong residual influence of anthropocentric thinking; less than half of biology majors showed a correct response pattern, and 38\% demonstrated an anthropocentric response pattern.

\subsubsection{Relations among Measures of Anthropocentric Thinking}

To examine relations among different measures of anthropocentric thinking, we computed standardized scores for sum of common ancestors, mean likelihood ratings for projections from humans, and number of anthropocentric responses for each participant. We reverse-scored the first two measures so that larger scores on all measures would ostensibly reflect more anthropocentric thinking (i.e., unwillingness to acknowledge common ancestry, unwillingness to project a human property to nonhumans, and anthropocentric construals of biological similarity). These measures were consistently intercorrelated; specifically, anthropocentric responding on the common ancestor task predicted anthropocentric responding on both the property projection task $(r(207)=0.40, p<0.001)$ and on the biological similarity task 
$(r(208)=0.26, p<0.001)$, and anthropocentric responding on the latter two tasks was also correlated, $r(210)=0.22, p=0.001$. This suggests that anthropocentric thinking may be a single underlying construct.

\subsection{Teleological Thinking}

To examine teleological thinking, we asked participants to rate their agreement with appropriate teleological explanations (e.g., "Pencils exist so that people can write with them"), inappropriate teleological explanations (e.g., "Houses have doorbells in order to make dogs bark") and natural kind teleological explanations (e.g., "Rain falls in order to allow plants to grow"). Each participant's ratings for appropriate, inappropriate, and natural kind explanations were averaged resulting in a score ranging from 1 (disagree) to 6 (agree) for each kind of statement. To examine the general degree of teleological thinking on this measure, we averaged agreement ratings across all three types of items, and compared groups on these scores via oneway ANOVA (see Figure 4A). On this analysis, biology majors were less likely to agree with statements than non-majors, who were less likely to agree than $8^{\text {th }}$ graders, $F(2,208)=21.03$, $p<0.001, \eta^{2}=0.17$, all differences $\mathrm{p}<0.017$ via Tukey HSD test.

$<$ Figure $4>$

To examine response patterns in more detail, we compared mean agreement ratings via 3 (Group) x 3 (Statement Type) mixed ANOVA. Several findings emerged in addition to the overall group differences discussed above. First, participants strongly agreed with appropriate statements and strongly disagreed with inappropriate statements; agreement for natural kind statements fell between the two $\left(F(2,416)=1646.01, p<0.001, \eta^{2}=0.88\right.$, all differences significant at $p<0.001$ via Bonferroni-corrected t-test). Second, the effects of group and statement were qualified by an interaction, $F(4,416)=10.01, p<0.001, \eta^{2}=0.01$ (see figure $4 \mathrm{~B}$ ). To examine this 
interaction, we conducted separate one-way ANOVAs comparing group performance separately for each type of question. Based on these tests, there were no group differences in agreement with appropriate items $(F(2,208)=1.88, p=0.155)$. In contrast, although mean ratings were all quite low, $8^{\text {th }}$ graders agreed more with inappropriate items than biology majors or non-majors, who did not differ $\left(F(2,208)=11.18, p<0.001, \eta^{2}=0.10\right.$, Tukey HSD $\left.p<0.027\right)$. Non-majors and $8^{\text {th }}$ graders did not differ in their agreement with natural kind items, and both exhibited higher agreement than biology majors $\left(F(2,208)=23.80, p<0.001, \eta^{2}=0.19\right.$, Tukey HSD $\left.p<0.001\right)$. Most notably, for all three groups, agreement for natural kind items was higher than agreement with inappropriate items $(t \geq 9.41, p<0.001, d \geq 1.13)$, indicating some endorsement for teleological thinking about natural phenomena.

To compare responses on different measures of teleological thinking, we conducted Pearson correlations on these scores. Results show consistent interrelations among the three measures. The strongest correlation was between agreement with with teleological explanations for natural kinds and inappropriate teleological explanations, $r(211)=0.50, p<0.001$. Agreement with appropriate teleological explanations was also positively correlated with agreement with inappropriate teleological explanations $(r(211)=0.19, p=0.005)$ and agreement with teleological explanations for natural kinds $(r(211)=0.22, p=0.001)$. The relatively strong positive correlation between agreement with inappropriate and natural kind teleological explanations is particularly informative, in that both are incorrect from a scientific point of view, but may indicate a stable underlying propensity toward teleological thinking.

\subsection{Essentialist Thinking}




\subsubsection{Category Homogeneity}

Participants were told that an individual member of a species (ant, grasshopper, giraffe, kangaroo) had a hypothetical intrinsic (X cells, gene X) or extrinsic (parasite X, bacteria X) property, and asked what percentage of all members of that species would share the property. To index essentialist thinking, we calculated the mean estimate for percentage of category members sharing an intrinsic property (novel cells or genes). One-way ANOVA revealed that groups differed in their homogeneity estimates, $F(2,190)=4.22, p=0.016, \eta^{2}=0.04$, see Figure $5 \mathrm{~A}$. Specifically, non-majors estimated that a higher percentage of species members would share an intrinsic property than $8^{\text {th }}$ graders (Tukey HSD $p=0.014$ ), whereas biology majors did not differ from either group (Tukey HSD $p>0.155$ ).

\section{$<$ Figure 5 $>$}

To examine responses in more detail, and because homogeneity estimates in isolation are hard to interpret in an absolute sense, we compared estimates for intrinsic versus extrinsic properties using a 3 (Group: $8^{\text {th }}$ graders, non-majors, biology majors) x 2 (property type: intrinsic, extrinsic) x 2 (Form: A, B) mixed ANOVA. We included form as a factor because the exemplars of intrinsic and extrinsic properties differed for forms A (cells and parasites, respectively) and B (genes and infection). Overall, as expected, homogeneity estimates were higher for intrinsic properties than extrinsic properties, $F(1,179)=110.18, p<0.001, \eta^{2}=0.36$. However, we also observed a property $\mathrm{x}$ group interaction $\left(F(2,179)=5.31, p=0.006, \eta^{2}=0.03\right)$, a main effect of form $\left(F(1,179)=14.07, p<0.001, \eta^{2}=0.07\right)$, and group $\mathrm{x}$ form interaction $\left(F(2,179)=3.25, p=0.041, \eta^{2}=0.03\right)$. Together, these suggest different responses for specific properties among the three groups. We explored this possibility via separate Form $\mathrm{x}$ Property Type ANOVAs for each group (see Fig 5B). 
For biology majors and non-majors, patterns were identical: homogeneity estimates for genes and cells were equivalent, and higher than for infections and parasites, which were also equivalent. This was affirmed by large main effects of property (non-majors: $F(1,62)=57.76$, $p<0.001, \eta^{2}=0.48$; biology majors: $\left.F(1,50)=38.06, p<0.001, \eta^{2}=0.43\right)$, no differences between forms, and no interaction. In contrast, for $8^{\text {th }}$ graders, estimates for cells were higher than for the other three properties, which were equivalent (see Fig. 5B). This was affirmed by main effects of property $\left(F(1,67)=18.22, p<0.001, \eta^{2}=0.20\right)$, form $\left(F(1,67)=19.41, p<0.001, \eta^{2}=0.22\right)$, and an interaction between the two $\left(F(1,67)=4.49, p=0.038, \eta^{2}=0.05\right)$. Lastly we compared homogeneity scores for all three groups on each property. No group differences were observed for cells, infection, or parasites $(F<1.20, p>0.307)$. In contrast, for gene, $8^{\text {th }}$ graders' scores were lower than both undergraduate groups, which did not differ $\left(F(2,90)=7.55, p=0.001, \eta^{2}=0.14\right.$, Tukey $\operatorname{HSD} p<0.005)$

To summarize, consistent with essentialist thinking, all groups perceived the target living kinds as more homogeneous with respect to intrinsic properties like cells than extrinsic properties like parasites or infections. Groups did not differ in perceived homogeneity for cells, but, unexpectedly, $8^{\text {th }}$ graders estimated much lower homogeneity for genes than for cells. In contrast, homogeneity estimates for gene and cell did not differ for biology majors or nonmajors.

\subsubsection{Innate Potential}

To probe individuals' thinking about innate potential, participants were given a scenario about a human infant born to one set of parents but raised by another, and asked which set of parents the child would more closely resemble. Responses indicating that the child would share characteristics with the birth parents, indicate essentialist thinking. To index essentialist thinking, 
we calculated the mean number of times (out a possible five) that participants said the child would more closely resemble the birth parents. One-way ANOVA revealed that groups did not differ in their responses, $F(2,208)=1.98, p=0.141 \eta^{2}=0.02$, see Figure 6 A.

$<$ Figure $6>$

To examine the data in more detail, we calculated the percentage of responses indicating resemblance to birth parents for each type of trait. Overall, participants' responses about the likelihood of resemblance to birth parents varied markedly by trait, ranging from $93 \%$ for physical traits to $6 \%$ for beliefs (see Figure $6 \mathrm{~B}$ ). We examined these data in two ways. First, we compared each cell to chance performance (50\%) via binomial test; above-chance performance suggests consensus that a trait is inherited - and thus subject to innate potential—whereas belowchance performance indicates that a trait is environmentally determined — and thus not subject to innate potential. Chance performance reflects lack of consensus. On this metric, all three groups believed that children were likely to resemble birth parents with respect to physical traits $(\mathrm{p}<0.001)$ and abilities $(\mathrm{p} \leq 0.008)$ and to resemble adoptive parents with respect to preferences $(\mathrm{p} \leq 0.001)$ and beliefs $(\mathrm{p}<0.001)$. For personality traits, beliefs were more equivocal. $8^{\text {th }}$ graders and biology majors believed that children were likely to resemble adoptive parents on personality traits $(\mathrm{p}<0.05)$, whereas non-majors responses as a whole didn't differ from chance $(p=0.904)$.

Second, to compare groups on specific types of traits, we conducted, a series of 3 (Group) x 2 (Response) Chi Square analyses for each type of trait. Only physical traits were close to significantly different, $X^{2}(2,211)=5.75, p=0.057^{2}$. Although a large majority of all participants thought that a child would resemblance its birth parents on physical traits, the proportion was

${ }^{2}$ This result should be interpreted with caution because $50 \%$ of the cells had an expected cell frequency of less than 5 . 
smaller for $8^{\text {th }}$ graders (88\%) than for biology majors $(97 \%)$ or non-majors $(96 \%)$. Group differences for other traits did not approach significance, $X^{2}(2)<4.27, p>0.118$. In sum, participants shared very similar reasoning about inherent potential for this set of traits.

\subsubsection{Identity over Transformation}

To assess individuals' thinking about the effects of transformations on category identity, participants were given two fictitious scenarios in which an animal underwent a transformation in appearance and behavior. In one, the transformation was a result of natural developmental process (akin to metamorphosis). In the other, the transformation was an artificial one triggered by exposure to toxic contamination. For each item, participants indicated on a scale whether the animal was biologically a member of the pre-transformation category or the post-transformation category both before the transformation and after the transformation.

To index essentialist thinking, we computed change scores for each participant by subtracting their pre-transformation category rating from their post-transformation category ratings. Thus, higher scores represent larger perceived effects of the transformation on category membership, whereas lower scores reflect more essentialist thinking. We conducted a 2 (Transformation: natural, artificial) x 3 (Group) mixed ANOVA on these change scores. Results revealed that $8^{\text {th }}$ graders' change scores were larger than those of biology majors $(F(2,203)=5.16$, $p=0.007, \eta^{2}=0.05$, Tukey HSD $\mathrm{p}=0.004$; non-majors scores were intermediate between these, and differed from neither (see Figure 7A). No effects of transformation type approached significance. One sample t-tests revealed that mean change scores for all three groups differed from zero, suggesting that all three groups readily accepted that transformations had an effect on category membership, $\left(8^{\text {th }}\right.$ graders: $t(73)=13.24, p<0.001, d=1.54$; non-majors: $t(67)=11.50, p<0.001$, $d=1.39$; biology majors: $t(67)=10.49, p<0.001, d=1.27)$. 
$<$ Figure $7>$

We further examined the degree of change between pre- and post-transformation ratings by dividing the response scale into three categorical responses indicating reasoning that the creature is a member of the pre-transformation category (1-3), reasoning that the creature is intermediate between the two categories (4-6), and reasoning that the creature is a member of the post-transformation category (7-9). We then characterized each participant's response to both pre- and post-transformation questions together as demonstrating category preservation (i.e., falling into the same response category pre- and post-transformation), category shift (i.e., moderate change, from pre-transformation category to intermediate, or intermediate to posttransformation category), or outright category change (from pre- to post-transformation category). For natural transformations, $38 \%$ of responses were consistent with essentialist thinking and involved category preservation, 19\% demonstrated a shift in perceived category membership, and 43\% reflected actual category change. A 3 (Group) x 3 (Response Pattern) Chi Square analysis revealed no group differences in response patterns, $X^{2}(4,208)=3.31, p=0.508$; see Figure 7B. For artificial transformations, $40 \%$ of responses involved category preservation, $20 \%$ demonstrated a shift in perceived category membership, and $40 \%$ reflected category change. A 3 (Group) x 3 (Response Pattern) Chi Square analysis revealed group differences in response patterns, $\left(X^{2}(4,207)=11.52, p=0.021\right.$. As depicted in Figure 7B, each group showed a distinctive response pattern. For $8^{\text {th }}$ graders, category change was the modal response, for non-majors, preservation and change were equally frequent, and for biology majors, category preservation was the modal response.

In sum, reasoning about transformations presented a mixed picture of essentialist thinking. Mean ratings suggest that participants readily accepted that both natural and artificial 
transformations changed category membership in these scenarios. Response patterns suggests that preservation of category membership was about as common as change of category membership, and that category shifts were more rare. Group differences were minimal, but suggested that $8^{\text {th }}$ graders were more willing to accept change in category membership, and hence can be characterized as less essentialist, than undergraduates.

\subsubsection{Absolute Category Membership}

This task examined reasoning about whether membership in intuitive biological categories (bird, fish, tree) is absolute (e.g., a given species must necessarily either be a bird or not be a bird) or graded (something could "sort of" be a bird). Each participant was given a score corresponding to the percentage of known exemplars to which they gave absolute responses (yes or no). As expected, scores were relatively high (see Figure 8A). Nevertheless, both undergraduate groups were more absolute in their category judgments than the $8^{\text {th }}$ graders, $F(2,208)=17.16, p<0.001, \eta^{2}=0.14$, Tukey HSD $p<0.001$. Biology majors and non-majors did not differ. This suggests stronger essentialist reasoning among undergraduates than among $8^{\text {th }}$ graders with respect to category boundaries.

\section{$<$ Figure $8>$}

To examine responses in more detail, we conducted a 3 (Group) x 3 (Category: Birds, Fish, Trees) mixed ANOVA on percentage of absolute category membership judgments. In addition to the overall group differences mentioned above, we also observed a group x category interaction, $F(4,416)=3.04, p=0.017, \eta^{2}=0.02$, see Fig. $8 \mathrm{~B}$. We explored this interaction via oneway ANOVAs comparing the three groups' responses for each category. For fish and trees, as in the overall analyses, biology majors and non-majors did not differ, and both gave a higher proportion of absolute responses than $8^{\text {th }}$ graders (fish: $F(2,208)=15.17, p<0.001, \eta^{2}=0.13$, Tukey 
HSD $p<0.001$; trees: $F(2,208)=6.38, p=0.002, \eta^{2}=0.06$, Tukey HSD $\left.p<0.022\right)$. For birds, biology majors gave a higher proportion of absolute responses than $8^{\text {th }}$ graders $(F(2,208)=3.28, p=0.040$, $\eta^{2}=0.03$, Tukey HSD $p=0.031$ ) but non-majors did not differ from either group (Tukey HSD $p>0.303)$.

\subsubsection{Relations Among Measures of Essentialist Thinking}

As a final analysis, we looked for interrelations among the five measures of essentialist thinking. To do so we ran correlation analyses on the indices of essentialist thinking for each measure: standardized scores for homogeneity estimates for intrinsic properties, sum of "birth parent" responses, percentage of absolute category judgments, and mean transformation difference scores (reverse-scored so that larger scores on all measures would reflect more essentialist thinking). For the most part, scores on these measures were unrelated, suggesting that essentialist thinking may not be a monolithic construct; results revealed a single significant correlation between essentialist responding on the transformation task and essentialist responding on the absolute category membership task, $r(210)=0.158, p=0.022$.

\subsection{Composite Analyses}

To construct composite measures for essentialist, anthropocentric, and teleological thinking, we computed standardized scores for all participants on each individual measure. We then averaged the scores for all measures corresponding to each construal, to obtain a single score for each participant on each construal-based set of measures. This score represents the degree to which an individual's responses to a set of measures reflects the corresponding cognitive construal, relative to all other participants. Finally, we compared $8^{\text {th }}$ graders, nonmajors, and biology majors on each composite score in order to assess the relative strength of each type of thinking for each group. Scores are depicted in Figure 9. 
$<$ Figure 9 $>$

The anthropocentric thinking composite measure was composed of an average of standardized scores representing (1) number of common ancestors (reverse scored), (2) mean likelihood rating for projection from humans (reverse scored), and (3) number of anthropocentric responses to triad items. One-way ANOVA showed that groups differed in their degree of anthropocentric responding, $F(2,208)=22.56, p<0.001, \eta^{2}=0.18$. Specifically, biology majors show less anthropocentric responding than either non-majors or $8^{\text {th }}$ graders (Tukey HSD $p>0.001$ ). Non-majors and $8^{\text {th }}$ graders differed only marginally (Tukey HSD $p=0.068$ ).

The teleological thinking composite measure was composed of an average of standardized scores representing mean agreement ratings for (1) appropriate teleological explanations, (2) inappropriate teleological explanations, and (3) teleological explanations for natural phenomena. One-way ANOVA showed that groups differed in their degree of teleological responding, $F(2,208)=17.99, p<0.001, \eta^{2}=0.15$. Specifically, $8^{\text {th }}$ graders responses were more teleological than those of non-majors (Tukey HSD $p=0.014$ ), whose responses were more teleological than biology majors (Tukey HSD $p=0.007$ ).

The essentialist thinking composite measure was composed of an average of standardized scores representing (1) estimates of homogeneity for intrinsic properties, (2) number of "birth parent" responses for switched-at-birth items, (3) absolute difference score for pre-post transformation ratings (averaged over natural and artificial transformations and reverse scored), and (4) percentage of absolute category judgments. One-way ANOVA showed that groups differed in their degree of essentialist responding, $F(2,208)=17.01, p<0.001, \eta^{2}=0.14$. Strikingly, $8^{\text {th }}$ graders' responses were less essentialist than those of biology majors or non- 
majors (Tukey HSD $p<0.001)$. Biology majors and non-majors didn’t differ in essentialist responding (see Fig. 9).

In addition to examining group differences, we also wanted to ascertain whether these construals reflect independent components of intuitive biological thought (as in Coley \& Tanner, 2015), or whether they were interrelated. To do so, we computed correlations between the three composite measures described above. These were computed separately for each age group, so that systematic group differences did not artificially influence correlations. Results are depicted in Table 2, and suggest that indeed, anthropocentric, teleological, and essentialist thinking are independent components of intuitive biological thought. The only significant correlation was a negative one between essentialist thinking and anthropocentric thinking for $8^{\text {th }}$ graders; no other correlations approached significance. Below, we will examine the degree to which individual sub-components are interrelated for each construal.

$<$ Table 2>

In sum, composite analyses reveal unique patterns of group differences for each intuitive cognitive construal. Specifically, $8^{\text {th }}$ graders and non-majors showed comparable levels of anthropocentric thinking, whereas biology majors showed much less. In contrast, all three groups differed in their degree of teleological thinking, with $8^{\text {th }}$ graders showing the most and biology majors showing the least. Interestingly, although differences in essentialist thinking were least pronounced, biology majors and non-majors showed comparable levels of essentialist thinking, and both showed stronger essentialist tendencies than $8^{\text {th }}$ graders. Finally, the lack of correlations among composite measures suggests that the three construals represent independent components of intuitive biological thought. 


\section{Discussion}

In this study we examined the nature of intuitive biological thinking in adolescence and early adulthood, and investigated the extent to which increasing amounts of biology education might influence intuitive biological thinking. To do so, we employed multiple measures to assess the prevalence of anthropocentric, teleological, and essentialist thinking in 8 th grade middle school students, first-year undergraduate biology majors who had earned Advanced Placement credit in biology, and undergraduates who were not biology majors and had earned Advanced Placement credit in a field other than biology. To our knowledge, this work is unique with respect to both the scope of measures utilized and the populations compared.

Several findings are of particular note. First, we find clear evidence of intuitive reasoning among all populations studied. Thus, our results firmly establish the persistence of intuitive biological reasoning — in the form of multiple cognitive construals - from $8^{\text {th }}$ grade into young adulthood. Given that these findings emerged across a broad range of measures, it suggests that intuitive reasoning is not simply a characteristic of a particular task or probe. For those who have primarily investigated cognitive development among younger age groups, these data may at first appear surprising. However, in recent years, a variety of research both in cognitive psychology

(e.g. Shtulman \& Schulz, 2008; Shtulman \& Valcarcel, 2012; Kelemen et al., 2013; Shtulman \& Harrington, 2016) and in science education (e.g. Coley and Tanner, 2015; Nehm \& Reilly, 2007) have begun to provide evidence that intuitive understandings may persist into adulthood.

Second, although we observed consistent differences between biology majors, nonmajors, and $8^{\text {th }}$ graders on measures of intuitive biological thought, these differences were surprisingly small given the differences in age, general cognitive development, and the increasing amounts of science education among our participant groups. For the most part, all 
three groups showed the same qualitative response patterns on tasks, and differences tended to be markedly smaller than effects of within-measure manipulations. This suggests that more extensive biology education may have relatively minimal influence on intuitive biological thinking. Below we discuss these findings in more detail for each of our target cognitive construals. We then briefly discuss implications and conclusions.

\subsection{Anthropocentric Thinking}

Results from our measures of anthropocentric thinking show that both undergraduate groups, as well as $8^{\text {th }}$ graders, responded in ways that suggest an underlying reasoning grounded in human exceptionalism. Consistent with anthropocentric thinking, participants in all three groups rarely attributed common ancestry with humans to any species apart from great apes, attributed novel genes from humans to non-humans only if the non-humans were perceived as sufficiently similar to humans, and overestimated human taxonomic uniqueness.

Although all three groups demonstrated anthropocentric thinking, group differences were also evident; whereas $8^{\text {th }}$ graders and non-majors showed few differences in anthropocentric thinking, both groups evinced more than biology majors. However, effect size for group differences were relatively small compared to effect size for within-task manipulations. For example, in the property projection measure of anthropocentric thinking, the effect size for the difference between target categories was 0.67 , whereas the effect sizes for the difference between groups and the interaction were 0.09 and 0.02 , respectively. This reveals that the common reasoning among all participants that species differ in their likelihood of sharing genes with humans was much stronger than difference among groups with respect to degree of likelihood or pattern of judgments. 
Biology majors appeared to employ anthropocentric reasoning, in spite of their more extensive formal training in biology. For example, while $8^{\text {th }}$ graders and non-majors asserted common ancestry between just humans and primates, biology majors went somewhat further in asserting common ancestry with both primates and mammals. However, biology majors were still far from asserting common ancestry of humans with all living creatures (see Figure 2). Less than half of biology majors asserted that humans shared a common ancestor with dinosaurs, birds, amphibians, insects, or plants, and qualitative drops in acknowledgement of shared ancestry with phylogenic distance were similar among all groups. These results are surprising given that a core tenet of evolution, which is central in formal biology education, is the common ancestry of all living organisms. However, these results on the common ancestry task suggest that anthropocentric reasoning persists despite intensive, college-level biology training.

Taken together, these results support prior research indicating that anthropocentric thinking persists into young adulthood (e.g., Coley, 2007; Johnson, et al., 1992; Goldberg \& Thomson-Schill, 2009) and extend it by showing that increasing amounts of biology education may have only a minimal effect on such thinking.

\subsection{Teleological Thinking}

Results of our measure of teleological thinking revealed evidence of this cognitive construal in all three groups. Specifically, all groups agreed more with teleological statements about natural kinds than with inappropriate statements, suggesting some willingness to accept technically incorrect teleological explanations for natural phenomena.

Again, group differences were evident; $8^{\text {th }}$ graders showed more teleological thinking than non-majors, who showed more than biology majors. Differences between 8th graders and undergraduates suggest a general reduction in the scope of what are viewed as appropriate 
teleological explanations with development (i.e., undergraduates are less teleologically promiscuous than 8th graders). Differences between non-majors and biology majors suggests that more intensive biology education may also play an additional role in reducing teleological thinking. These findings support those of Kelemen's argument that teleological thinking persists but becomes less "promiscuous" with development (e.g., Kelemen and Rossett, 2009; Kelemen et al., 2013). Nevertheless, group differences were again relatively small. The effect size for differences in agreement with different classes of teleological explanation was 0.88 , whereas the effect size for the difference between groups and the interaction were 0.17 and 0.01 , respectively, showing that the common thinking among all participants about the differences in acceptability of different teleological explanations was much stronger than differences among groups in agreement with those explanations.

Biology majors also demonstrated use of teleological reasoning to explain natural phenomena. Although they were less likely than non-majors to agree with scientifically inaccurate "natural kind" teleological statements, biology majors were more accepting of these statements than they were of inaccurate teleological statements that were about general, nonbiological topics, suggesting some persistence of teleological reasoning about natural phenomena. These results suggest that increasing amounts of biology education may decreasebut not eliminate-teleological reasoning. This is consistent with the hypothesis that persistence of teleological thinking into the college years may underlie systems of biological misconceptions, namely inaccurate biological reasoning that may cross disparate topic areas such as physiology, evolution, and molecular biology, yet have in common threads of teleological reasoning (Coley \& Tanner, 2015; Kelemen \& Rosset, 2009). 


\subsection{Essentialist Thinking}

Essentialist thinking was also evident across age and biology education; participants in all three groups expected biological kinds to be more homogeneous with respect to intrinsic properties than extrinsic properties, believed that biological properties and abilities were likely to be driven by nature rather than nurture, and thought that membership in most bird, fish, and tree categories we asked about was absolute.

Surprisingly, $8^{\text {th }}$ graders demonstrated lower levels of essentialist thinking than biology majors or non-majors, who did not differ. This suggests that essentialist reasoning about biology may actually increase with development through adolescence, and may do so relatively independently of increasing amounts of biology education. Previous research suggests that essentialist thinking may become increasingly focused on the domain of biology with development (e.g., Taylor et al., 2009); because we focused exclusively on intuitive biological reasoning, our results may reflect that tendency.

As with the other construals, group differences were relatively small. For example, for the category homogeneity measure of essentialist thinking, the effect size for the difference between student groups was 0.04 , yet the effect size for the differences between intrinsic and extrinsic properties was 0.36 , an order of magnitude larger. This shows that the common reasoning among all participants that intrinsic properties like cells were likely to be more homogenous than extrinsic properties like parasites and infections far outweighed the difference among groups with respect to the degree of homogeneity of genes.

On multiple measures of essentialist thinking, biology majors were statistically indistinguishable from their college-age peers with less intensive and advanced biology education experiences. For example, the innate potential measure (switched-at-birth task) probed 
students' predictions about whether a child's characteristics - physical characteristics, abilities, and beliefs - would be more like their birth parents or their adoptive parents. Results on this essentialist measure were strikingly similar between the two college-age populations under study. This is surprising given that advanced, college-level biology education would likely include explorations of epigenetics - the impact of the environment on gene expression and inherited traits. Indeed, one might have predicted that biology majors—presumably with some prior exposure to the concept of gene expression and the interplay of the environment with genetics — might be less willing than non-majors to endorse a strong "nature" view of a child's properties. For example, over two-thirds of all college-age students, including biology majors, asserted that a child's aptitude for particular sports (soccer v swimming) or academic subject (English v math) would resemble that of their birth parents, which reflects minimal attention to environmental effects on growth, development, and learning. Even for physical traits, a child's height would be dependent not only on genetics, but also on environmental variables such as available nutrition. Yet, over $90 \%$ of all college-age students asserted that a child's height would be more similar to their birth parents than their adoptive parents (see also Ware \& Gelman, 2014). These results suggest that intensive, college-level biology education has minimal influence on essentialist reasoning, resulting in biology majors that are highly similar in their essentialist reasoning to non-majors, even in biological contexts.

These findings raise questions about relations between increasing amounts of biology education and essentialist thinking. Unlike anthropocentric and teleological thinking, essentialist thinking was higher among college students than $8^{\text {th }}$ graders, and did not differ for biology majors versus non-majors. One possible interpretation of this finding is that - unlike anthropocentric and teleological thinking - in some respects essentialist thinking may be 
consistent with normative scientific biological understanding. For example, one might argue that essentialist responses such as maintaining category identity over transformations, or believing that a hypothetical gene is likely to be shared widely among a species, or believing that membership in biological categories is absolute, are biologically correct. Alternatively, essentialist thinking may lead to perceptions of category homogeneity, and corresponding underestimates of natural variability, contrary to what Mayr (1982) calls "population thinking." In other words, the (correct) understanding that biological species have a genetic basis canwhen coupled with a penchant for essentialist thinking - may give rise to the incorrect supposition that a particular gene is likely to be widely shared within a species. Likewise, essentialist thinking may lead to perceptions of sharp, discrete category boundaries among classes of living things, which is inconsistent with the idea that all living things are related via descent from a common ancestor (e.g., O’Hara, 1998; for further discussion of these issues, see Coley \& Muratore, 2012; Gelman \& Rhodes, 2012). In sum, relations between essentialist thinking and scientific understanding may be quite complex.

Finally, we found that measures of essentialist thinking were less cohesive than measures of anthropocentric or teleological thinking; individual measures were largely independent of each other. We see two implications of this finding. First, it raises questions about conceptualizing essentialist thinking as a unitary construct. The work of Haslam and colleagues (e.g., Haslam, Rothschild and Ernst, 2000) in the realm of social categorization suggests that essentialist thinking may be profitably analyzed into distinct subcomponents of naturalness - the degree to which concepts are seen as objective, discreet and stable--and cohesiveness (“entitativity") — the degree to which concepts are seen as homogeneous and informative. Perhaps essentialist thinking in intuitive biology might be profitably analyzed into similar 
orthogonal subcomponents. Although our measures were not designed to examine this possibility directly, our finding that innate potential (arguably related to category naturalness) is independent of perceived category homogeneity (a measure of cohesiveness) is consistent with this idea. Second, this finding raises procedural questions about employing a single measure of essentialist thinking in studies of intuitive biology. Typically, such studies have relied on a single measure of performance; however, our results demonstrate that essentialist thinking may not be a unidimensional construct. At the very least, relations among measures of essentialist thinkingand by proxy, among potential components of the construct—are ripe for further investigation.

\subsection{Limitations and Extensions}

Although the results presented here are intriguing, the investigations need to be replicated among additional populations at similar developmental and educational levels. The results presented were collected from single populations of students from two educational institutions. Future studies should attempt to replicate these findings with students at other institutions that are geographically and culturally diverse.

Relatedly, we do not claim that our list of construals is exhaustive; other cognitive construals relevant to intuitive biological thought most certainly exist. One excellent candidate is vitalist thinking (e.g., Hatano \& Inagaki, 1994; Morris, Taplin \& Gelman, 2000; Inagaki \& Hatano, 2002). Nor do we claim that these three construals are universal. Although some of the construals we examined might be relatively robust to cultural and contextual differences (Casler \& Kelemen, 2008; Rottman et al, 2015; Sousa, Atran \& Medin, 2004; Atran \& Medin, 2008), others might well vary with culture or other contextual factors (i.e., anthropocentric thinking: Ross et al., 2003; Waxman, Medin \& Ross, 2007; Medin et al., 2010; Herrmann et al., 2010); teleological thinking: ojalehto, Waxman \& Medin, 2013). Indeed, both the content of intuitive 
biology and the patterns of developmental change might vary for different populations. For now, these remain open, and important, questions.

It is also important to emphasize that biology majors in this study were in their first semester of college biology. Although they had all previously demonstrated achievement in biology through success on the AP biology exam-a commonly accepted metric of understanding of basic biological principles which is often substituted for completion of a college-level biology course - the present results should be taken as an examination of the impact of advanced, intensive biological studies in high school on intuitive thinking. It may well be that more college-level coursework in the life sciences in a higher-education context would lead to a continued reduction in the use of intuitive cognitive construals among more advanced biology majors, and a corresponding reduction in similarity between majors and non-majors. In fact, analysis of performance of disciplinary experts in biology - arguably an endpoint of cognitive development within biology as a conceptual area - may provide an important touchstone for considering relations between intuitive biological reasoning and formal training in the biological sciences. Although some recent work has revealed evidence of implicit effects of intuitive knowledge even among highly trained practicing scientists (Kelemen, et al., 2013; Shtulman \& Harrington, 2016; Goldberg \& Thomson-Schill, 2009), it remains to be seen how the acquisition of formal disciplinary expertise in biological science affects performance on more explicit tasks like those employed here.

An important related question raised by these findings is the degree to which biology majors hold multiple frameworks of biology knowledge (e.g., Legare, Evans, Rosengren \& Harris, 2012; Shtulman \& Valcarcel, 2012). Perhaps biology majors possess the formal biology knowledge to respond in a way that is less indicative of intuitive cognitive construals, but simply 
did not deploy such knowledge in this context on our tasks. On the face of it, this seems somewhat unlikely, because many of the items were transparently biological in nature, and because biology majors were tested during their biology classes. However, future investigations are necessary to differentiate these possibilities.

\subsection{Conclusions}

By systematically utilizing a broad array of measures of intuitive biological reasoning, we have shown clear evidence of persistent, explicit intuitive reasoning among college students as well as 8th graders. Differences among student groups, although consistently significant, were small and tended to be markedly smaller than effects of within-measure manipulations for each task. Perhaps more surprisingly, increasing amounts of formal biology education had a much smaller impact on intuitive reasoning than one might have anticipated. Despite showing a quantitative reduction in construal-based reasoning, biology majors often showed the same qualitative pattern of responses as non-majors and 8th graders.

Elsewhere we have argued that cognitive construals involved in intuitive biological thought may provide the foundation for systems of misconceptions common to students in the biology classroom (Coley \& Tanner, 2012) and presented evidence for systematic linkages between construal-based thinking and biological misconceptions in both biology majors and nonmajors (Coley \& Tanner, 2015). Taken together with those results, the current study underscores the impact of intuitive knowledge in the science classroom, and raises important questions about the effects of science education on conceptual understanding more generally. Intuitive biological reasoning is systematic and pervasive; consideration of such informal conceptual systems that students bring with them into the biology classroom might greatly enhance our understanding of how we learn formal biological science, and in turn how best to teach it. Addressing these and 
other related research questions will require increasingly interdisciplinary approaches that integrate the theories, methods, and traditions of both cognitive science and science education research. 


\section{Acknowledgements}

This research was funded by National Science Foundation EHR Core Research Grant \#1535496

to J.D. Coley and K.D. Tanner. We thank Sarah Bissonnette for comments on the manuscript. 


\section{References}

Ahn, W., Kalish, C., Gelman, S. A., Medin, D. L., Luhmann, C., Atran, S., Coley, J. D. \& Shafto, P. (2001). Why essences are essential in the psychology of concepts. Cognition, $82,59-69$.

Arenson, M.B. \& Coley, J.D. (2016). Anthropocentric Thinking About Familiar and Novel Properties. Poster presented at the $28^{\text {th }}$ Annual Convention of the Association for Psychological Science, Chicago IL.

Asher, R. J., Bennett, N. \& Lehmann, T. 2009. The new framework for understanding placental mammal evolution. BioEssays 31, 853-864.

Atran, S.A. \& Medin, D.L. (2008). The native mind and the cultural construction of nature. Boston: MIT Press.

Berlin, B. (1992). Ethnobiological classification: Principles of categorization of plants and animals in traditional societies. Princeton, NJ: Princeton University Press.

Brown, C. H. (1984). Language and living things: Uniformities in folk classification and naming. New Brunswick, NJ: Rutgers University Press.

Carey, S. (1985). Conceptual change in childhood. Cambridge, MA: MIT Press.

Casler, K. \& Kelemen, D. (2008). Developmental continuity in the teleo-functional bias: Reasoning about nature among Romanian Roma adults (Gypsies). Journal of Cognition and Development, 9, 340-362.

Chi, M. T. H. (1992). Conceptual change in and across ontological categories: Examples from learning and discovery in science. In R. Giere (Ed.), Cognitive Models of Science (pp. 129-160). Minneapolis. MN: University of Minnesota Press. 
Coley, J. D. (2000). On the importance of comparative research: the case of folkbiology. Child Development, 71, 82-90.

Coley, J. D. (2007). The human animal: developmental changes in judgments of taxonomic and psychological similarity among humans and other animals. Cognitive Brain Behavior, 11, $733-756$.

Coley, J. D. \& Muratore, T.M. (2012). Trees, Fish, and Other Fictions: Folk Biological Thought and its Implications for Understanding Evolutionary Biology. In K. S. Rosengren, S. Brem, E. M. Evans, \& G. Sinatra (Eds.). Evolution challenges: Integrating research and practice in teaching and learning about evolution (22-46). Cambridge: Oxford University Press.

Coley, J. D., Solomon, G. E. A. \& Shafto, P. (2002). The development of folkbiology: a cognitive science perspective on children's understanding of the biological world. In: Children and Nature: Psychological, Sociocultural and Evolutionary Investigations, ed. P Kahn and S Kellert, Cambridge, MA: MIT Press, 65-91.

Coley, J. D., \& Tanner, K. (2012). Common Origins of Diverse Misconceptions: Cognitive Principles and the Development of Biology Thinking. Cell Biology Education, 11(3), 209-215.

Coley, J. D., \& Tanner, K. (2015). Relations between Intuitive Biological Thinking and Biological Misconceptions in Biology Majors and Nonmajors. Cell Biology Education, $14,1-19$.

Coley, J.D. \& Vasilyeva, N.Y. (2010). Generating inductive inferences: Premise relations and property effects. In B.H. Ross (Ed.) The Psychology of Learning and Motivation, 53, 183-226. Burlington MA: Academic Press. 
Diesendruck, G., \& Gelman, S. A. (1999). Domain differences in absolute judgments of category membership: Evidence for an essentialist account of categorization. Psychonomic Bulletin and Review, 6, 338-346

DiSessa, A. A. (1993). Toward an epistemology of physics. Cognition and Instruction, 10(2\& 3), $105-225$.

Eidson, R. C., \& Coley, J. D. (2014). Not so fast: gender essentialism in young adults. Journal of Cognitive Development, 15, 382-292.

Emmons, N. A., \& Kelemen, D. (2015). Young children's acceptance of within-species variation: Implications for essentialism and teaching evolution. Journal of Experimental Child Psychology, 139, $148-160$.

Evans, E. M. (2008). Conceptual change and evolutionary biology: A developmental analysis. In S. Vosniadou (Ed.), International Handbook of Research on Conceptual Change. Pp. 263-294. New York: Routledge

Evans, E. M. (2013). Conceptual change and evolutionary biology: Taking a developmental perspective. In S. Vosniadou (Ed.,). International Handbook of Research on Conceptual Change. pp. 220-239. New York, NY: Routledge. [Second Edition]

Evans, E. M., Rosengren, K., Lane, J. D., \& Price, K. S. (2012). Encountering counterintuitive ideas: constructing a developmental learning progression for biological evolution. In: Evolution Challenges: Integrating Research and Practice in Teaching and Learning about Evolution, ed. KS Rosengren, S Brem, EM Evans, and G Sinatra, New York: Oxford University Press, 174-199.

Feeney, A. \& Heit, E. (Eds.). (2007). Inductive reasoning. Cambridge: Cambridge University Press. 
Gee, H. (2013). The Accidental Species: Misunderstandings of Human Evolution. Chicago, IL: University of Chicago Press.

Gelman, S. A. (2003). The Essential Child: Origins of Essentialism in Everyday Thought, New York: Oxford University Press.

Gelman, S., \& Coley, J.D. (1990). The importance of knowing a dodo is a bird: Categories and inferences in 2-year-old children. Developmental Psychology, 26(5), 796-804.

Gelman, S.A., \& Markman, E.M. (1986) Categories and induction in young children, Cognition, 23,183-209.

Gelman, S.A., \& Rhodes, M. (2012). "Two-thousand years of stasis": How psychological essentialism impedes evolutionary understanding. In K.R. Rosengren, S. Brem, E.M. Evans, \& G. Sinartra (Eds). Evolution challenges: Integrating research and practice in teaching and learning about evolution (pp. 3-21). New York: Oxford University Press.

Gelman, S., \& Wellman, H. (1991). Insides and essences: Early understandings of the nonobvious. Cognition, 38(3), 213-244.

Goldberg, R., \& Thompson-Schill, S. (2009). Developmental "Roots" in Mature Biological Knowledge. Psychological Science, 20(4), 480-487.

Hampton, J., Estes, Z., \& Simmons, S. (2007). Metamorphosis: Essence, appearance, and behavior in the categorization of natural kinds. Memory \& Cognition, 35(7), 1785-1800.

Haslam, N., Rothschild, L., \& Ernst, D. (2000). Essentialist beliefs about social categories. British Journal of Social Psychology, 39(1), 113-127.

Hatano, G., \& Inagaki, K. (1994). Young children's naive theory of biology. Cognition, 50, 171188. 
Herrmann, P., Waxman, S. R., \& Medin, D. L. (2010). Anthropocentrism is not the first step in children's reasoning about the natural world. Proceedings of the National Academy of Sciences, 107(22), 9979-9984.

Inagaki, K., \& Hatano, G. (1991). Constrained person analogy in young children's biological inference. Cognitive Development, 6, 219-231.

Inagaki, K., \& Hatano, G. (2002). Young Children's Nä̈ve Thinking about the Biological World. New York: Psychology Press.

Inagaki, K., \& Hatano, G. (2006). Young Children's Conception of the Biological World. Current Directions in Psychological Science, 15(4), 177-181.

Inagaki, K., \& Sugiyama, K. (1988). Attributing human characteristics: Developmental changes in over- and under-attribution. Cognitive Development, 3, 55-70.

Johnson, S. C. \& Carey, S. (1998). Knowledge enrichment and conceptual change in folk biology: Evidence from people with Williams syndrome. Cognitive Psychology, 37, 156200.

Johnson, K. E., Mervis, C. B., \& Boster, J. S. (1992). Developmental changes within the structure of the mammal domain. Developmental Psychology, 28, 74-83.

Kalish, C.W. (2002). Essentialist to some degree: Beliefs about the structure of natural kind categories. Memory \& Cognition, 30, 340-352.

Keil, F. C. (2006). Explanations and understanding. Annual Review Psychology, 57, 227-254.

Keil, F. C. (1989). Concepts, kinds, and cognitive development. Cambridge, MA: MIT Press.

Kelemen, D. (1999). The scope of teleological thinking in preschool children. Cognition, 70, $241-272$. 
Kelemen, D. (2004). Are children "intuitive theists"? Reasoning about purpose and design in nature. Psychological Science, 15, 295-301.

Kelemen, D. (2012). Teleological minds: how natural intuitions about agency and purpose influence learning about evolution. In ed. KS Rosengren, SK Brem, EM Evans, and GM Sinatra, Eds., Evolution Challenges: Integrating Research and Practice in Teaching and Learning about Evolution. New York: Oxford University Press.

Kelemen, D., \& Rossett, E. (2009). The human function compunction: teleological explanation in adults. Cognition, 111, 138-143.

Kelemen, D., Rottman, J., \& Seston, R. (2013). Professional physical scientists display tenacious teleological tendencies: Purpose-based reasoning as a cognitive default. Journal of Experimental Psychology: General, 142(4), 1074-1083.

Leddon, E., Waxman, S. R., Medin, D. L, Bang, M. \& Washinawatok, K. (2012). One animal among many? Children's understanding of the relation between humans and nonhuman animals. In G. Hayes \& M. Bryant (Eds.), Psychology of Culture. In Psychology of emotions, motivations and actions: Focus on civilizations and cultures series. Hauppauge, NY: Nova Science Publishers.

Legare, C., Evans, E., Rosengren, K., \& Harris, P. (2012). The Coexistence of Natural and Supernatural Explanations Across Cultures and Development. Child Development, 83(3), $779-793$.

Lombrozo, T., \& Carey, S. (2006). Functional explanation and the function of explanation. Cognition, 99, 167-204. 
Madsen, O., Scally, M., Douady, C. J., Kao, D. J., DeBry, R. W., Adkins, R., Amrine, H. M., Stanhope, M. J., de Jong, W. W. \& Springer, M. S. 2001. Parallel adaptive radiations in two major clades of placental mammals. Nature 409, 610-614.

Maeyer, J., \& Talanquer, V. (2010). The role of intuitive heuristics in students' thinking: Ranking chemical substances. Science Education, 94(6), 963-984.

Mayr, E. (1982). The growth of biological thought: Diversity, evolution, and inheritance. Cambridge,MA: Harvard University Press.

Medin, D., \& Atran, S. (2004). The Native Mind: Biological Categorization and Reasoning in Development and Across Cultures. Psychological Review, 111(4), 960-983.

Medin, D. L., \& Ortony, A. (1989). Psychological essentialism. In: Similarity and Analogical Reasoning, ed. S Vosniadou and A Ortony, Cambridge, New York Cambridge University Press, 179-195.

Medin, D., Waxman, S., Woodring, J., \& Washinawatok, K. (2010). Human-centeredness is not a universal feature of young children's reasoning: Culture and experience matter when reasoning about biological entities. Cognitive Development, 25(3), 197-207.

Morris, S.C., Taplin, J.E. \& Gelman, S.A. (2000). Vitalism in naïve biological thinking. Developmental Psychology, 36 (5), 582-595.

Nehm, R.H. (2010). Understanding undergraduates’ problem-solving processes. Journal of Microbiology \& Biology Education, 11 (2), 119.

Nehm, R., \& Reilly, L. (2007). Biology Majors' Knowledge and Misconceptions of Natural Selection. BioScience, 57 (3), 263.

Nehm, R.H. \& Ridgway, J. (2011). What do experts and novices "see” in evolutionary problems? Evolution: Education and Outreach, 4 (4), 666-679. 
ojalehto, b., Waxman, S., \& Medin, D. (2013). Teleological reasoning about nature: intentional design or relational perspectives? Trends in Cognitive Sciences, 17(4), 166-171.

O’Hara, R.J. (1998). Population thinking and tree thinking in systematics. Zoologica Scripta, 26, 323-329.

Opfer, J.E., Nehm, R.H., \& Ha, M. (2012). Cognitive foundations for science assessment design: knowing what students know about evolution. Journal of Research in Science Teaching, $49(6), 744-777$.

Piaget, J. (1929). The child's conception of the world. London: Routledge \& Kegan Paul.

Richards, D., \& Siegler, R. S. (1986). Children's understandings of the attributes of life. Journal of Experimental Child Psychology, 42, 1-22.

Rips, L. J. (1989). Similarity, Typicality, and Categorization, in S, Vosniadou. \& N, Ortony. (Eds.) (pp. 21-59), Similarity and Analogical Reasoning. Cambridge: Cambridge University Press.

Rosengren, K.R., Brew, S., Evans, E.M. \& Sinatra, G., Eds. (2012) Evolution challenges: Integrating research and practice in teaching and learning about evolution. New York: Oxford University Press.

Ross, N., Medin, D., Coley, J., \& Atran, S. (2003). Cultural and experiential differences in the development of folkbiological induction. Cognitive Development, 18(1), 25-47.

Rottman, J., Zhu, L., Wang, W., Seston Schillaci, R., Clark, K. J., \& Kelemen, D. (2016). Cultural influences on the teleological stance. Evidence from China. Religion, Brain \& Behavior, in press. doi: 10.1080/2153599X.2015.1118402.

Shtulman, A. (2006). Qualitative Differences Between Naïve And Scientific Theories Of Evolution. Cognitive Psychology, 52 (2), 170-194. 
Shtulman, A., \& Harrington, K. (2016). Tensions between science and intuition across the lifespan. Topics in Cognitive Science, 8 (1), 118-137.

Shtulman, A., \& Schulz, L. (2008). The Relation Between Essentialist Beliefs and Evolutionary Reasoning. Cognitive Science, 32(6), 1049-1062.

Shtulman, A., \& Valcarcel, J. (2012). Scientific knowledge suppresses but does not supplant earlier intuitions. Cognition, 124(2), 209-215.

Sousa, P., Atran, S., \& Medin, D.L. (2002). Essentialism and folkbiology: Evidence from Brazil. Journal of Cognition and Culture, 2(3), 195-223.

Solomon, G., Johnson, S., Zaitchik, D., \& Carey, S. (1996). Like Father, like Son: Young Children's Understanding of How and Why Offspring Resemble Their Parents. Child Development, 67(1), 151.

Talanquer, V. (2013). When Atoms Want. Journal of Chemical Education, 90(11), 1419-1424.

Talanquer, V. (2009). On Cognitive Constraints and Learning Progressions: The case of “structure of matter”. International Journal of Science Education, 31(15), 2123-2136.

Talanquer, V. (2006). Commonsense chemistry: a model for understanding students' alternative conceptions. Journal of Chemical Education, 83, 811-816.

Taylor, M., Rhodes, M., \& Gelman, S. (2009). Boys Will Be Boys; Cows Will Be Cows: Children's Essentialist Reasoning About Gender Categories and Animal Species. Child Development, 80(2), 461-481.

Vosniadou, S., \& Brewer, W.F. (1992). Mental models of the earth. A study of conceptual change in childhood. Cognitive Psychology, 24, 535-585. 
Ware, E.A. \& Gelman, S.A. (2014). You Get What You Need: An Examination of PurposeBased Inheritance Reasoning in Undergraduates, Preschoolers, and Biological Experts. Cognitive Science, 38, 197-243.

Waxman, S., Medin, D., \& Ross, N. (2007). Folkbiological reasoning from a cross-cultural developmental perspective: Early essentialist notions are shaped by cultural beliefs. Developmental Psychology, 43(2), 294-308. 


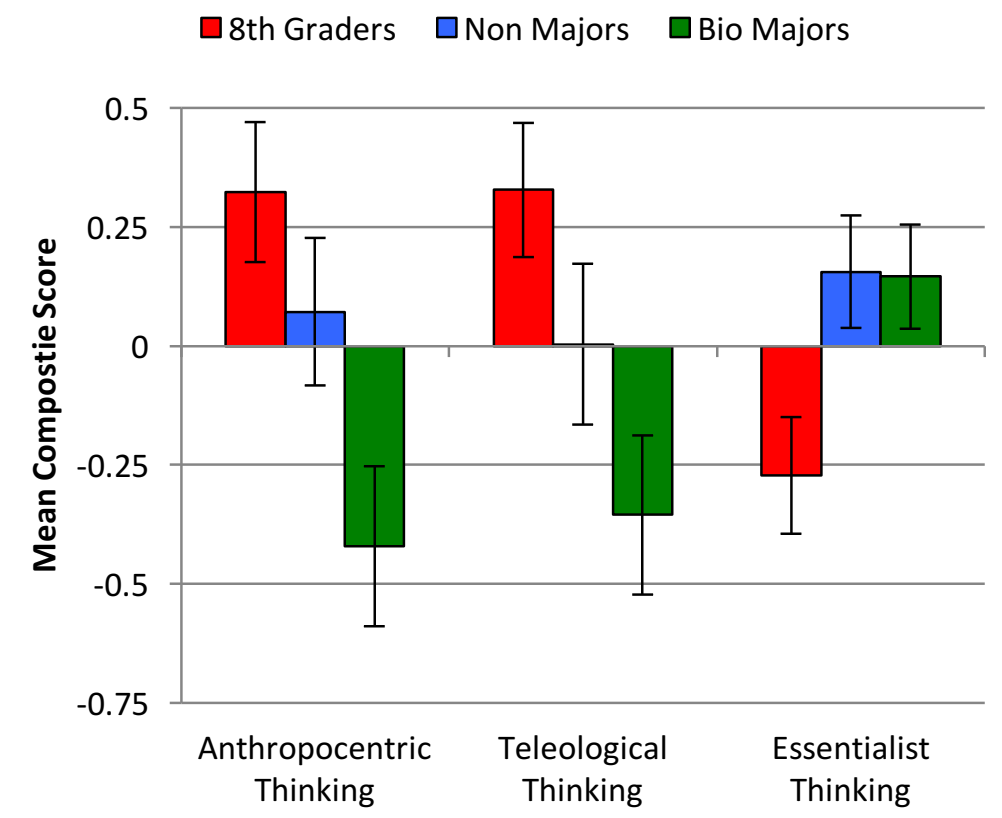

Figure 1: Composite scores summarizing relative performance on measures of anthropocentric, teleological, and essentialist thinking for $8^{\text {th }}$ graders, non-majors, and biology majors. Error bars represent 95\% CI. 

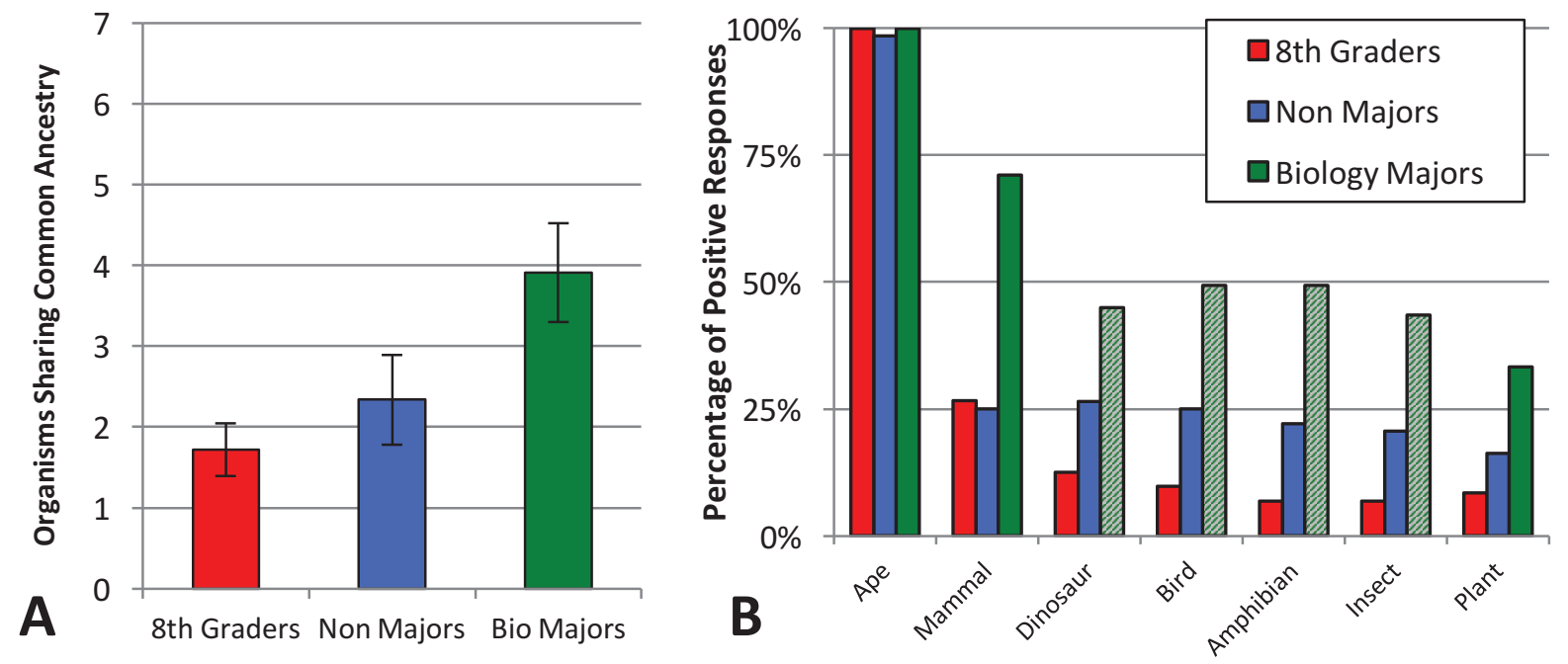

Figure 2: Anthropocentric Thinking, Common Ancestor Task. (A) Mean number of organisms said to share a common ancestor with humans. (Note: Error bars correspond to $95 \%$ confidence intervals). (B) Percentage of positive responses for each target species on the common ancestor task for $8^{\text {th }}$ graders, non-majors, and biology majors. Note: bars with diagonally-lined fill did not differ from chance $(50 \%)$ via binomial test. 

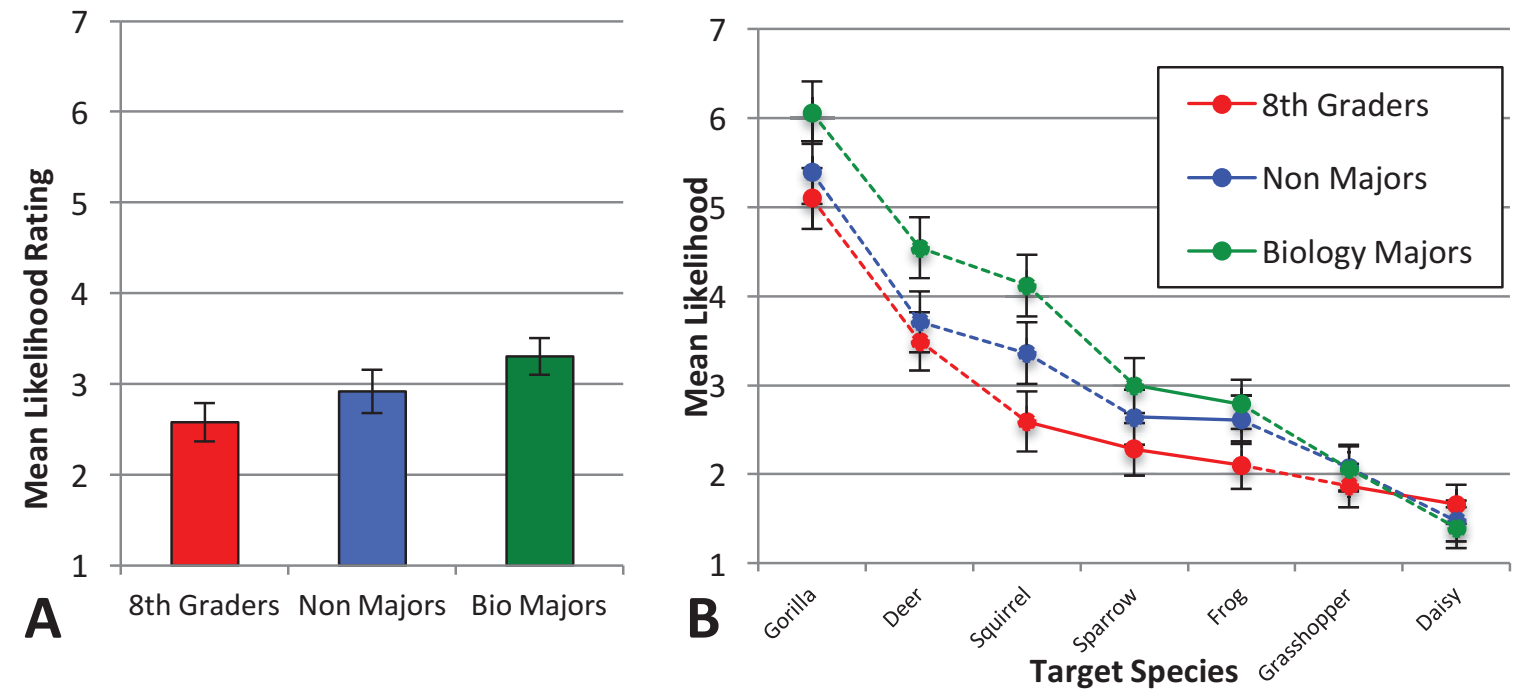

Figure 3: Anthropocentric Thinking, Property Projection Task. (A) Mean likelihood, averaged across targets, that a target species would share a hypothetical gene with humans for $8^{\text {th }}$ graders, non-majors, and biology majors. (B) Mean likelihood that each target species would share a hypothetical gene with humans for $8^{\text {th }}$ graders, non-majors, and biology majors. Note: error bars represent $95 \%$ confidence intervals; points connected by dotted lines differed reliably (LSD $p<0.008)$; points connected by solid lines did not. 

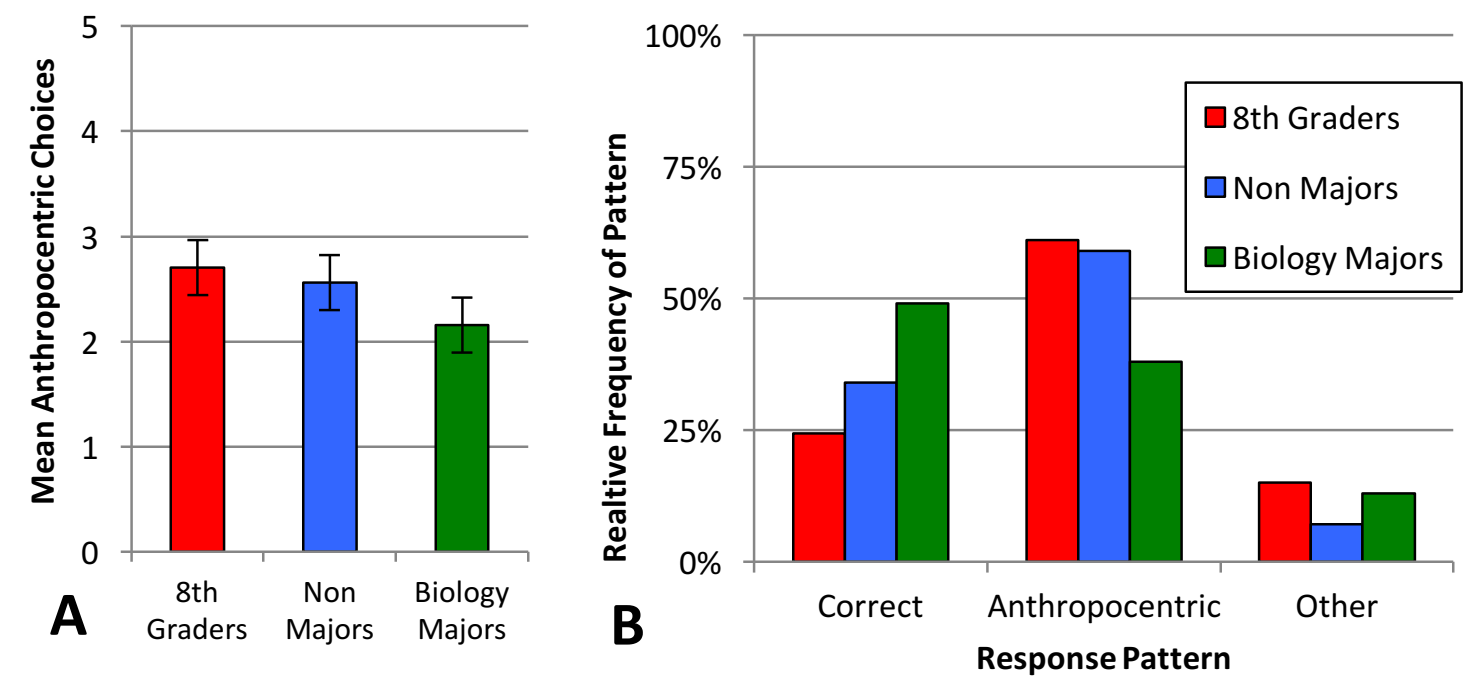

Figure 4: Anthropocentric Thinking, Biological Similarity Task. (A) Mean number of anthropocentric choices on the biological similarity task. Note: error bars represent $95 \%$ confidence intervals. (B) Percentage of $8^{\text {th }}$ graders, non-majors and biology majors showing correct, anthropocentric, and other response patterns across all five items for the biological similarity task. 

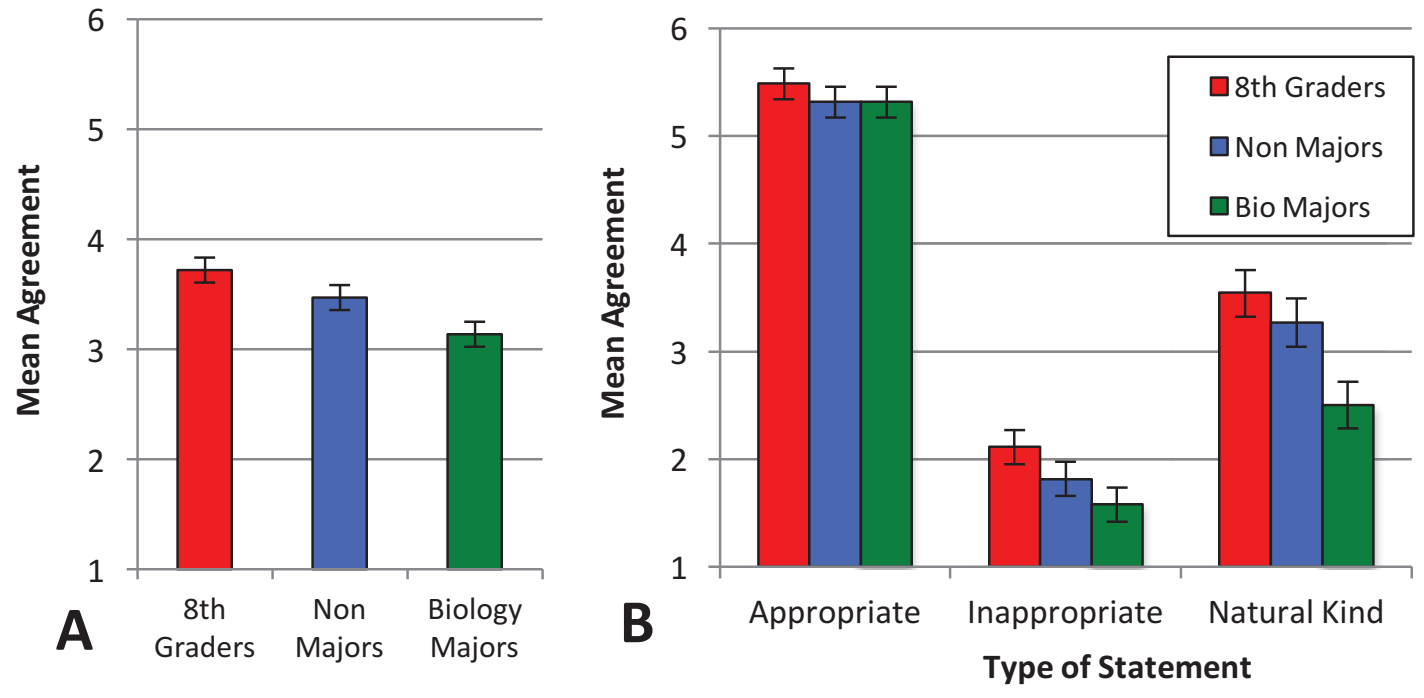

Figure 5: Teleological Thinking, Agreement with Explanations Task. (A) Overall mean agreement with teleological statements for $8^{\text {th }}$ graders, non-majors and biology majors. (B) Mean agreement with appropriate, inappropriate and natural kind teleological statements for $8^{\text {th }}$ graders, non-majors and biology majors. Note: error bars represent $95 \%$ confidence intervals. 

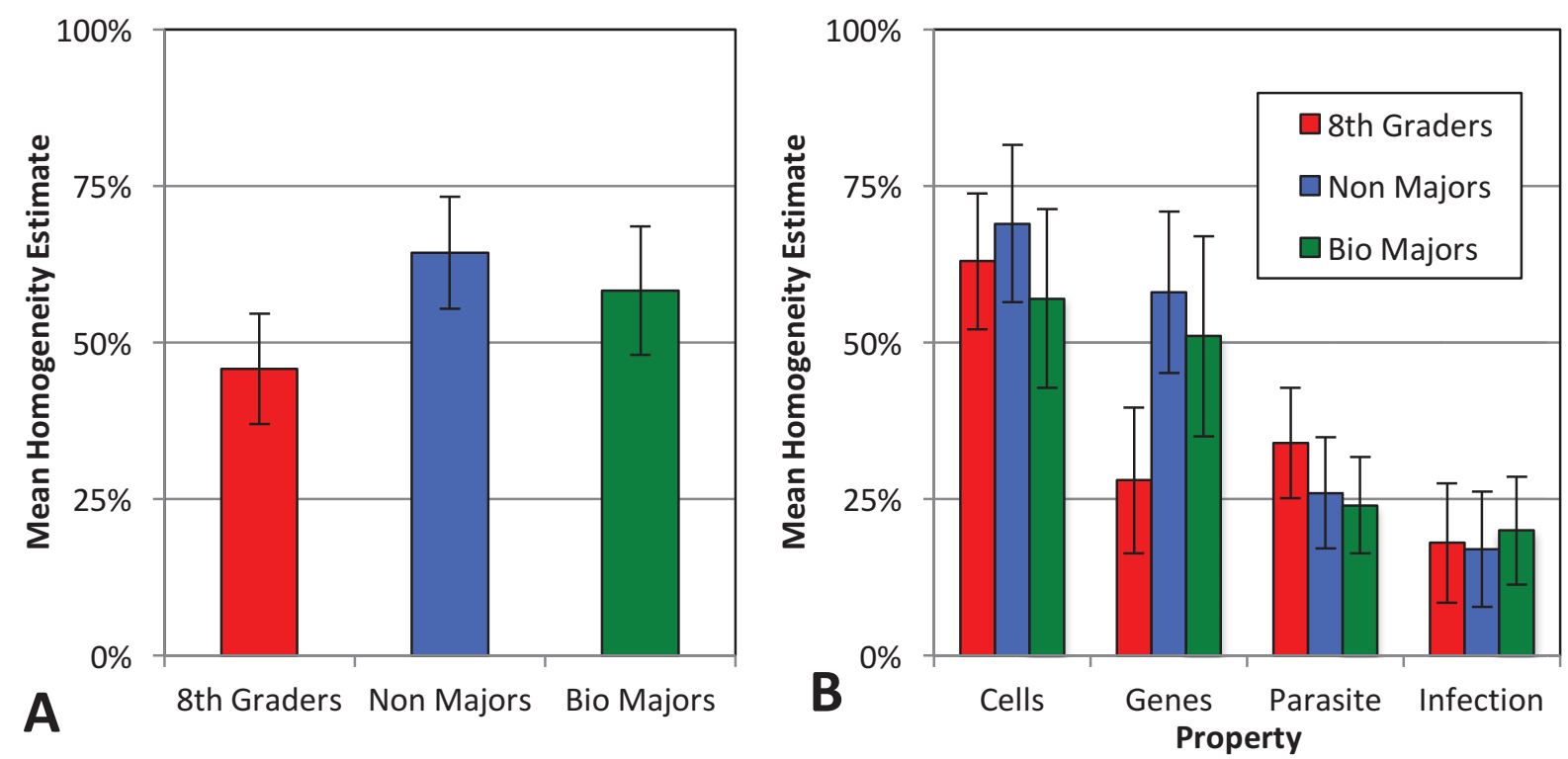

Figure 6: Essentialist Thinking, Category Homogeneity Task. (A) Mean homogeneity estimates for intrinsic properties (novel cells or genes) for $8^{\text {th }}$ graders, non-majors and biology majors. (B) Mean estimates of percentage of a species sharing hypothetical intrinsic properties (cells, genes) and extrinsic properties (parasite, infection) for $8^{\text {th }}$ graders, non-majors and biology majors. Note: Error bars represent 95\% confidence intervals. 

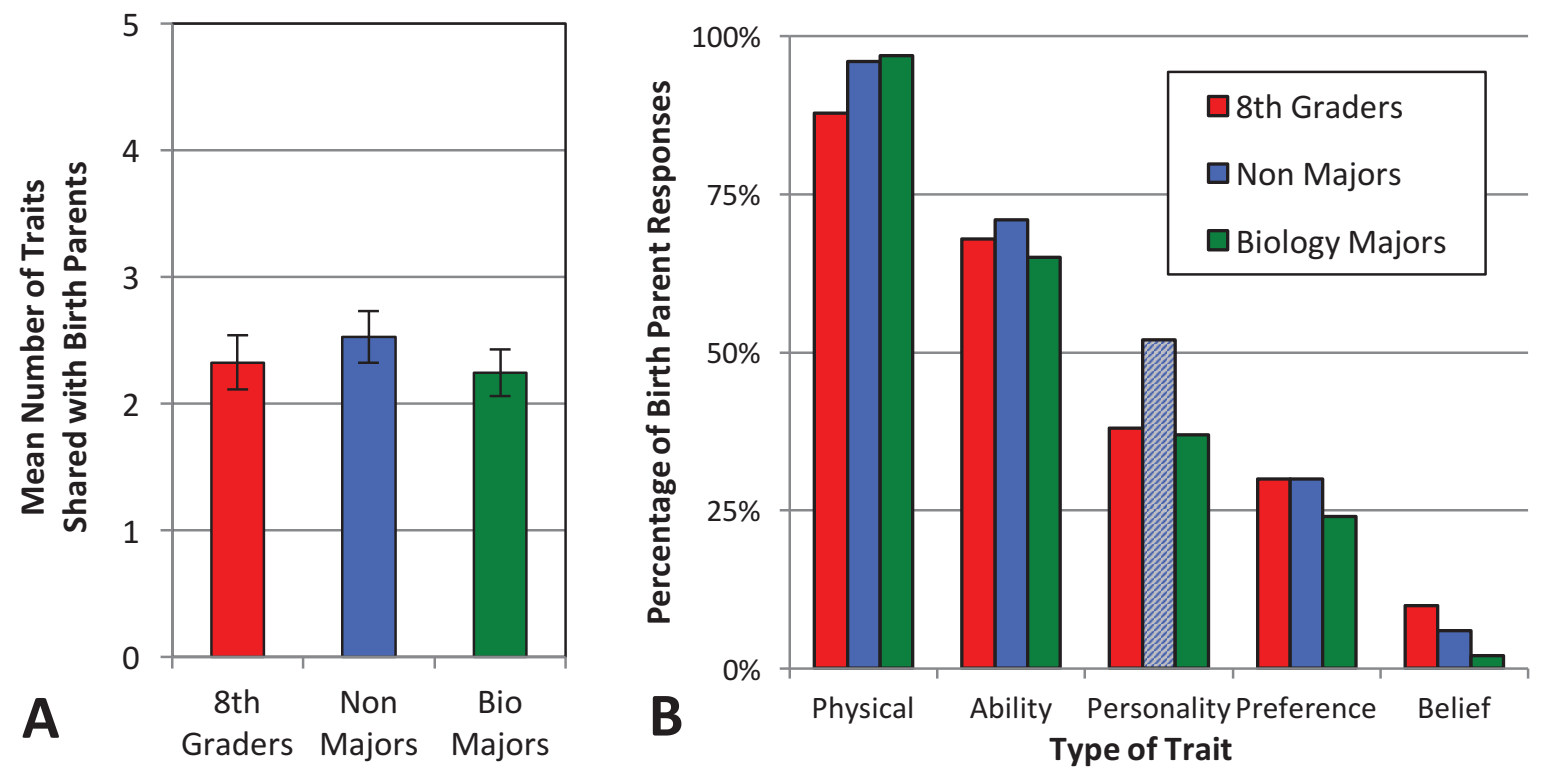

Figure 7: Essentialist Thinking, Innate Potential Task. (A) Mean number of traits that $8^{\text {th }}$ graders, non-majors and biology majors predicted that a child would share with birth parents. (Note: Error bars represent $95 \%$ confidence intervals.) (B) Percentage of $8^{\text {th }}$ graders, non-majors and biology majors indicating resemblance to birth parents for each type of trait. Note: bars with diagonallylined fill did not differ from chance (50\%) via binomial test. 

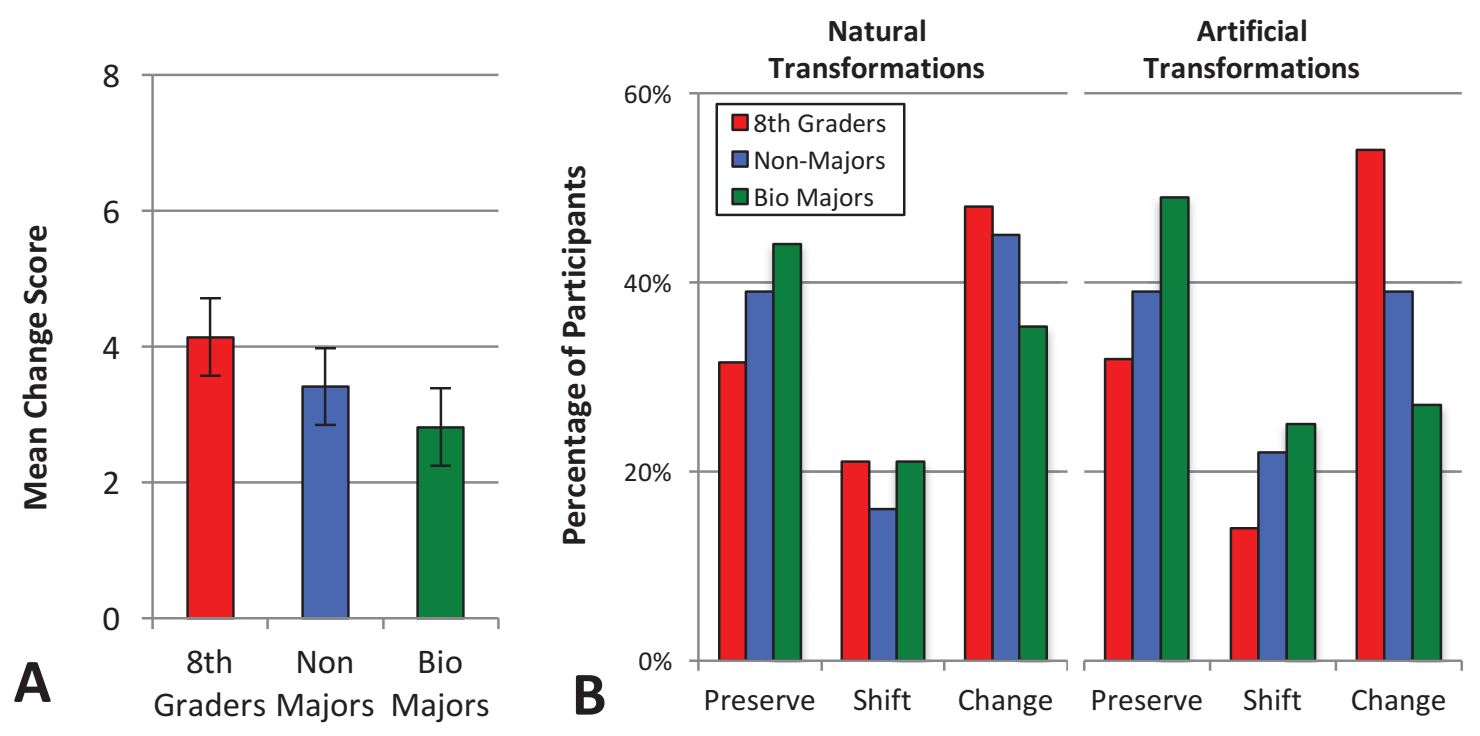

Figure 8: Essentialist Thinking, Transformation Task. (A) Mean pre-post transformation change scores averaged over natural and artificial transformations. (Note: Error bars correspond to 95\% confidence intervals). (B) Percentage of participants in each group showing category preservation, shift, and change patterns for natural and artificial transformation scenarios. 

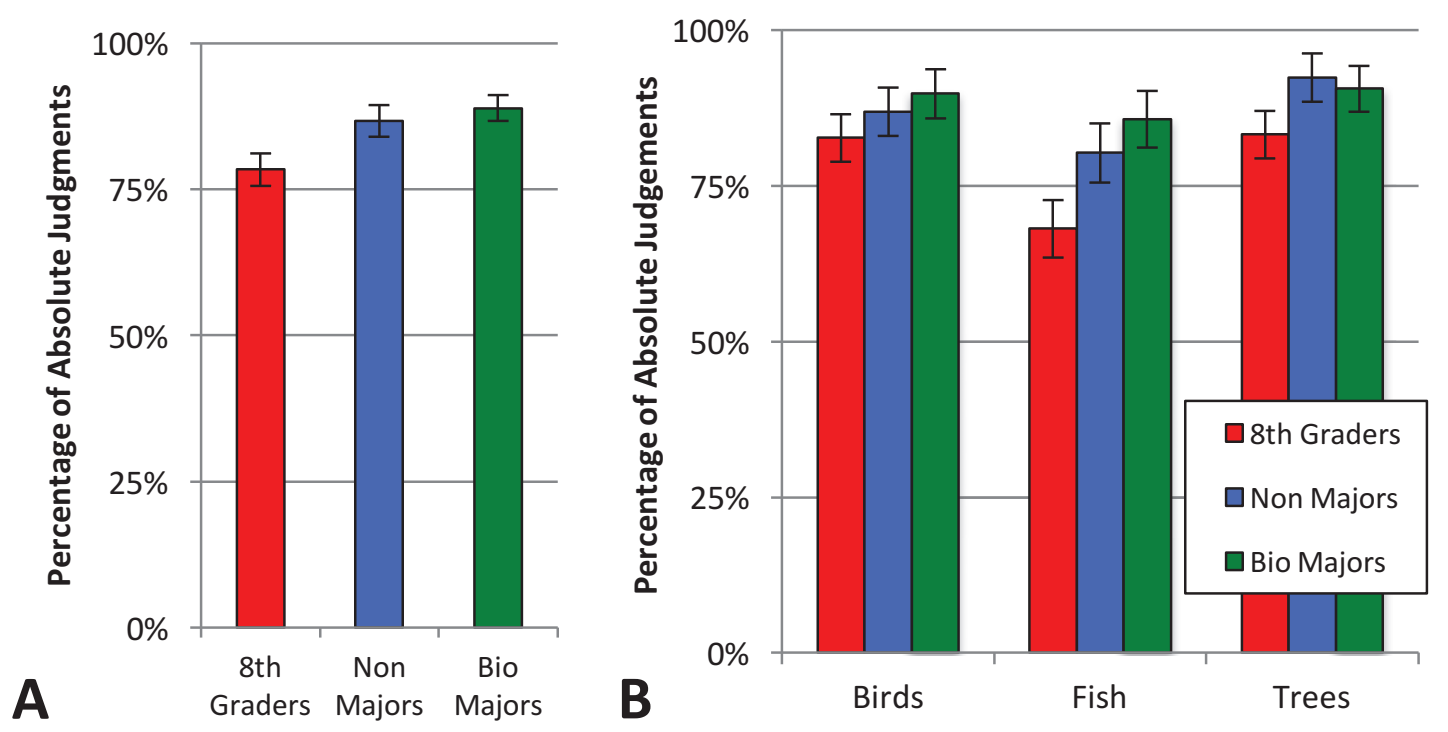

Figure 9: Essentialist Thinking, Absolute Category Membership Task. (A) Overall percentage of absolute category judgments for each group. (B) Percentage of absolute category judgments for bird, fish, and tree categories for each group. Note: Error bars correspond to $95 \%$ confidence intervals. 